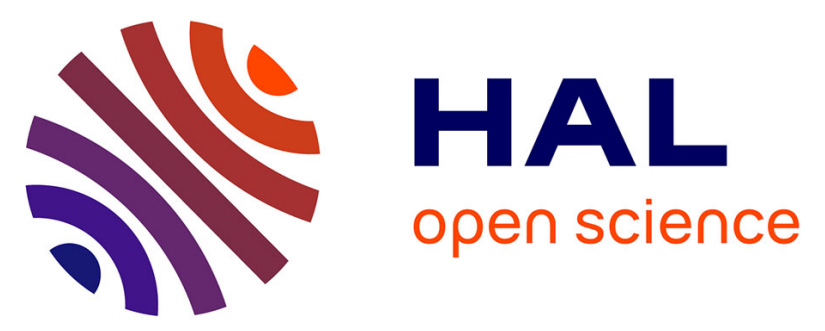

\title{
Selective identification of cyclopentaring-fused PAHs and side-substituted PAHs in a low pressure premixed sooting flame by photoelectron photoion coincidence spectroscopy
}

\author{
X. Mercier, A. Faccinetto, S. Batut, G. Vanhove, D. Božanić, H. \\ Hróðmarsson, G. Garcia, L. Nahon
}

\section{To cite this version:}

X. Mercier, A. Faccinetto, S. Batut, G. Vanhove, D. Božanić, et al.. Selective identification of cyclopentaring-fused PAHs and side-substituted PAHs in a low pressure premixed sooting flame by photoelectron photoion coincidence spectroscopy. Physical Chemistry Chemical Physics, 2020, 22 (28), pp.15926-15944. 10.1039/D0CP02740E . hal-03016086

\section{HAL Id: hal-03016086 https://hal.science/hal-03016086}

Submitted on 20 Nov 2020

HAL is a multi-disciplinary open access archive for the deposit and dissemination of scientific research documents, whether they are published or not. The documents may come from teaching and research institutions in France or abroad, or from public or private research centers.
L'archive ouverte pluridisciplinaire $\mathbf{H A L}$, est destinée au dépôt et à la diffusion de documents scientifiques de niveau recherche, publiés ou non, émanant des établissements d'enseignement et de recherche français ou étrangers, des laboratoires publics ou privés. 

substituted PAHs in a low pressure premixed sooting flame by photoelectron

Authors: X. Mercier ${ }^{*}$, A. Faccinetto ${ }^{1}$, S. Batut $^{1}$, G. Vanhove $^{1}$, D. K. Bozanic ${ }^{2 \dagger}$, H. R.

Hrodmarsson $^{2,}$, G. A. Garcia ${ }^{2}$, L. Nahon ${ }^{2}$

Affiliations:

${ }^{1}$ Université Lille, CNRS, UMR 8522 - PC2A - Physicochimie des Processus de Combustion et de l'Atmosphère, F59000 Lille, France,

${ }^{2}$ Synchrotron SOLEIL, L ‘Orme des Merisiers, St. Aubin, BP 48, 91192 Gif sur Yvette, France

*Correspondence to: Xavier Mercier (xavier.mercier@univ-lille.fr). Tel: + 33320434804

${ }^{\dagger}$ Current institutional address: Vinča Institute of Nuclear Sciences, University of Belgrade, P.O. Box 522, 11001 Belgrade, Serbia

${ }^{\ddagger}$ Current institutional address: Laboratory for Astrophysics, Leiden Observatory, Leiden University, PO Box 9513, NL-2300 RA Leiden, The Netherlands

\section{Abstract:}

This work reports on the selective on-line identification of polycyclic aromatic hydrocarbons (PAHs) formed in a low-pressure methane sooting flame, carried out using the double imaging Photoelectron Photoion Coincidence Spectroscopy method (i ${ }^{2}$ PEPICO) on the DESIRS VUV beamline at the synchrotron SOLEIL. Generally, this work demonstrates the capabilities of the $i^{2}$ PEPICO method to identify PAHs in sooting flames, and in particular to distinguish cyclopentaring-fused PAHs (CP-PAHs) and side-substituted PAHs from their benzenoid isomers. Experimental threshold photoelectron spectra of four CP-PAHs: acenapthylene $\left(\mathrm{C}_{12} \mathrm{H}_{8}\right.$, $152 \mathrm{~m} / \mathrm{z})$, acenaphtene $\left(\mathrm{C}_{12} \mathrm{H}_{10}, \quad 15\right.$ $54 \mathrm{~m} / \mathrm{z})$, fluoranthene $\left(\mathrm{C}_{16} \mathrm{H}_{10}, \quad 202 \mathrm{~m} / \mathrm{z}\right)$ and benzo(ghi)fluoranthene $\left(\mathrm{C}_{18} \mathrm{H}_{10}, 226 \mathrm{~m} / \mathrm{z}\right)$ are also reported for the first time. 
30 Keywords: threshold photoelectron spectroscopy (TPES), electron/ion coincidence, polycyclic 31 aromatic hydrocarbons (PAHs), soot, nucleation 


\section{Introduction}

Soot particles released at the exhaust of combustion processes are subject to special attention because of their well-documented detrimental impact on the human health and environment. Soot particles in the atmosphere are at the origin of allergic rhinitis and other affections of the respiratory system ${ }^{1}$. Many hydrocarbons adsorbed at the surface of soot particles and formed during the combustion process are known to be toxic and to have mutagenic and/or carcinogenic health effects ${ }^{2,3}$, and the inhalation of soot particles has been correlated to a wide variety of acute and chronic diseases ${ }^{4}$. In the environment, especially when released in the high troposphere by aeronautic jet engines for instance, soot particles impact the radiative forcing of the atmosphere as they can absorb and scatter the solar radiation (direct effect) or act as cloud/ice condensation nuclei and trigger the formation of persistent clouds (indirect effect), thereby affecting the local climate $^{5,6}$. The detailed chemical characterization of soot particles can therefore provide crucial information to better assess their toxicity and atmospheric reactivity, and furthermore, help to clarify their formation process, which so far is not completely understood.

The formation of soot particles in flames is known to be strongly correlated to reaction pathways involving polycyclic aromatic hydrocarbons (PAHs), which are considered the main precursors of soot particles. Although the growth of PAHs is widely accepted to be driven by the HACA mechanism ${ }^{7}$ (Hydrogen Abstraction Acetylene Addition), alternative reaction pathways have also been suggested ${ }^{8-13}$. In order to evaluate the relative importance of these pathways, experimental data are needed to, firstly, unambiguously identify the chemical species involved in the soot formation process, and secondly, to measure their in-flame concentrations. However, recent atomic force microscopy experiments ${ }^{14}$ demonstrated that the growth process of PAHs naturally results in the formation of a variety of structural isomers that can be found adsorbed on the soot particles surface. At a given mass, structural isomers of PAHs can be very difficult to discriminate with traditional analytical techniques as their number rapidly increases with the 
number of carbon atoms in the molecule ${ }^{15}$. In-situ laser based methods such as laser induced florescence (LIF) can generally provide qualitative data about PAH formation in flames, as well as the PAH class size and their localization in the flame ${ }^{16-22}$, but such methods are incapable of unfolding the contributions of individual species. It has been recently shown that better discrimination can be achieved by using relatively simple spectral models for the interpretation of the experimental fluorescence spectra that rely on the use of tabulated fluorescence spectra of individual PAHs ${ }^{23,24}$. Not only these methods allow the identification of the main PAHs formed in flames, but in particularly favorable cases they can even distinguish between structural isomers such as pyrene and fluoranthene. However, such approaches do not yet allow quantitative measurements. The determination of mole fraction profiles of PAHs in flames by LIF indeed requires ex-situ measurements, such as those provided by complex laboratory setups like Jet-Cooled Laser Induced Fluorescence (JCLIF) ${ }^{25,26}$. However, JCLIF requires fine adjustment of the excitation laser wavelength to a resonant transition of a specific target $\mathrm{PAH}$, which limits the measurement capability to a few PAHs having well-known spectral properties, and to only one isomeric structure at a time.

In comparison, mass spectrometry-based methods based on time-of-flight are multiplex in mass, and allow the simultaneous measurement of all the molecular species in the sample but can generally not distinguish structural isomers. In addition, the high ionization energies used in typical setups based on electron impact lead to complex fragmentation patterns that complicate the identification of the parent ions. In this context, tunable vacuum ultraviolet (VUV) radiation, such as the one provided by synchrotron-based techniques, is an attractive way to obtain selective PAHs concentration profiles in flames because of its ability to distinguish structural isomers $^{27-30}$ via spectral discrimination, and to avoid or limit the amount of fragmentation by ionizing close to the threshold. Different research groups highlighted the capabilities of such techniques for the selective and quantitative measurement of species formed in rich flames ${ }^{31-34}$. 
In the cited works, unknown species are identified through their photoionization efficiency (PIE) curve, which consists of the integrated ion signal against the photon energy. The first ionization of PAHs commonly leads to the formation of stable molecular cations that can be detected independently by mass spectrometry. Therefore, a PIE curve recorded for a specific mass with tunable Synchrotron Radiation (SR) in the range of, and immediately above the first ionization energy of PAHs $(I E=7-11.5 \mathrm{eV})$ in principle allows the identification of structural isomers once their individual spectral contribution are known ${ }^{28,31,34-36}$. However, these curves integrate over all available states of the cation at a given photon energy, and therefore lack sufficient spectral structures to deliver an unambiguous interpretation, especially when several isomers coexist at the same $m / z$ and have close $I E$ values. This is notably the case of $m / z=152$, studied in this work, which is generally associated to four different main isomers ${ }^{37}$ in flame investigations: biphenylene $(I E=7.58 \mathrm{eV}, \mathbb{C})$, acenaphthylene $(I E=8.02 \mathrm{eV}, 0)$, 1-ethynylnaphthalene $(I E=8.11 \mathrm{eV}, \circlearrowleft)$ and 2-ethynylnaphthalene $\left(I E=8.03 \mathrm{eV},{ }^{\prime \prime}\right)$. In this case, the distinction between acenaphthylene and 2-ethynylnaphthalene based only on their PIE curves is impossible. We note, however, that in some cases identification can be greatly helped by the appearance of autoionization features in the PIE curves, such as the ones seen for coronene ${ }^{38}$.

As a first approximation, ignoring autoionization resonances, a PIE curve corresponds to the integral of the photoelectron spectrum (PES) at a given photon energy and therefore contains much less sharp spectroscopic features, i.e. possesses a much weaker analytical ability in disentangling structural isomer ions detected at the same $\mathrm{m} / \mathrm{z}$. For this reason, photoelectronphotoion coincidence spectroscopy (PEPICO) has been demonstrated in the last years to be a powerful tool for the identification of structural isomers in complex gas-phase environments such as flames, combustion reactors and oxidation chambers ${ }^{39-47}$. This technique enables the recording of photoelectron spectra (PES) of the mass-selected ionized detected species. Because of the richer vibronic structure as compared to PIE curves, the PES acts as a unique fingerprint 
107 providing unambiguous information about its structure ${ }^{43,48}$. Such a fine analysis of complex

108 mixtures via mass-selected PES is based upon the comparison with either known experimental

109 PES of pure compounds or, alternatively, PES obtained from ab-initio calculations. Notably,

110 Felsmann et al. $^{41}$ demonstrated the capabilities, including the sensitivity, of the double imaging

111 photoelectron photoion coincidence spectrometer $i^{2} \mathrm{PEPICO}$ technique for the identification of

112 different structural isomers formed in dimethyl ether and cyclopentene flames. They identified

113 for the first time without ambiguity in the low pressure cyclopentene flame, the contributions of

114 1-penten-3-yne in competition with the much larger signal of 1,3-cyclopentadiene. Different

115 other aromatic species up to $128 \mathrm{~m} / \mathrm{z}$ were also detected.

116 The aim of this work is to explore the capabilities of the $i^{2} \mathrm{PEPICO}$ method for the detection 117 of PAHs in sooting flames, more specifically focusing on the identification of gas phase PAHs

118 isomers formed in the nucleation region of a sooting flame. This study has been carried out on 119 the DESIRS VUV beamline at the SOLEIL synchrotron by using the permanent $i^{2}$ PEPICO-based 120 experimental setup SAPHIRS, which was coupled to a low pressure premixed $\mathrm{CH}_{4} / \mathrm{O}_{2} / \mathrm{N}_{2}$ 121 sooting flame stabilized at the pressure $p=26.66 \mathrm{kPa}$ (200 torr), with an equivalence ratio $\phi=2.32$.

122 This flame was chosen for several reasons. First, it has already been the subject of several studies 123 by some of the co-authors dedicated to PAHs and soot formation ${ }^{25,49-54}$ with a variety of 124 diagnostics, therefore providing an ideal benchmark case for the present work. Second, this 125 flame is a lightly sooting flame characterized by a soot volume fraction profile reaching values 126 of the order of a few ppb in the burnt gases ${ }^{53}$. The study of sooting flames with the $i^{2}$ PEPICO 127 setup introduces an additional difficulty for sampling measurements in comparison to the non128 sooting flames studies reported above. Because of the formation of soot particles, the clogging of 129 the sampling probe becomes a critical issue during the recording of photoelectron spectra that 130 can take up to several hours. The choice of this lightly sooting flame was also aimed at limiting 131 this issue. Note, however, that contrary to PIE curves where the photon energy needs to be 
132 scanned and thus a high reactor stability is required, fixed-photon energy photoelectron

133 spectroscopy can also be recorded with the $i^{2}$ PEPICO setup. This approach can be much faster

134 and overcomes the need for stability, albeit at the expense of energy resolution, as discussed

135 further in the text and demonstrated in the context of flames ${ }^{41,43}$.

136 To demonstrate the capability of the $i^{2}$ PEPICO setup for PAH measurements and isomer

137 discrimination in sooting flames, we specifically focused on the nucleation region of the flame,

138 i.e. the zone where the first nascent soot particles (NSPs) are formed. One specific outcome of 139 this work was to clearly highlight the formation of cyclopentaring-fused-PAHs (CP-PAHs)

140 whose structure contains five-membered carbon rings, which have already been proposed in the

141 literature to be important intermediates on the formation of NSPs ${ }^{11,12,55-58}$. CP-PAHs often share

142 the same molecular formula as six-membered ring PAHs, and are thus impossible to distinguish

143 with common mass spectrometry setups. Moreover, we were also interested in revealing the

144 presence, or absence, of side-substituted PAHs in the sampled gases. The $\mathrm{i}^{2}$ PEPICO setup

145 provides a unique possibility to record the PES for each of the peaks on the mass spectra

146 simultaneously, allowing the identification of the formed PAHs via their electronic fingerprints,

147 provided that individual PES of the detected species are known. PES of small hydrocarbons are

148 globally well documented in the literature, which makes their identification straightforward.

149 However, the number of isomers quickly increases with the size of the molecule making the

150 identification of larger molecules, such as PAHs more complex. In particular, the selective

151 identification of some of these PAH isomers required the measurement of the PES of several

152 pure CP-PAHs which not available in the literature at the time of our experiments. Hence, the

153 PES of fluoranthene $\left(\mathrm{C}_{16} \mathrm{H}_{10}, 202 \mathrm{~m} / z\right)$, acenaphthylene $\left(\mathrm{C}_{12} \mathrm{H}_{8}, 152 \mathrm{~m} / z\right)$, acenaphthene $\left(\mathrm{C}_{12} \mathrm{H}_{10}\right.$,

$154154 \mathrm{~m} / \mathrm{z})$ and benzo(ghi)fluoranthene $\left(\mathrm{C}_{18} \mathrm{H}_{10}, 226 \mathrm{~m} / \mathrm{z}\right)$ are also reported for the first time in this 155 paper. 
The experimental setup we used can be operated in two modes: (1) the threshold-PES mode enabling the determination of the PES by scanning the photon energy while selecting only quasizero kinetic energy electron and (2) the PES mode in which the full PES is encoded into a single electron image recorded at fixed photon energy. In both modes all the masses are acquired simultaneously, providing mass-selected TPES and PES data. A comparison between the results

161 obtained with these two different modes of operation is also reported in this paper. Benefits, 162 capabilities and limitations of both modes for PAHs, side-substituted PAHs and CP-PAHs identification are then discussed.

\section{Experimental Setup}

\subsection{Experimental setup used for the determination of PES and PIE curves of} acenaphthene, acenaphthylene, fluoranthene and benzo(ghi)fluoranthene

In order to enable the analysis of specific detected masses and especially highlight the presence of some CP-PAHs, the measurement of PES and PIE curves of four CP-PAHs currently 171 missing in the literature and likely formed in sooting flames has been carried out in this work.

172 These species of interest were acenaphthylene $\left(\mathrm{C}_{12} \mathrm{H}_{8}, 152 \mathrm{~m} / z\right)$, acenaphthene $\left(\mathrm{C}_{12} \mathrm{H}_{10}, 154 \mathrm{~m} / z\right)$, 173 fluoranthene $\left(\mathrm{C}_{12} \mathrm{H}_{10}, 202 \mathrm{~m} / \mathrm{z}\right)$ and benzo(ghi)fluoranthene $\left(\mathrm{C}_{18} \mathrm{H}_{10}, 226 \mathrm{~m} / z\right)$.

174 The spectra of these species have been recorded by depositing the pure CP-PAHs (98-99\% 175 purity, Aldrich) in an in-vacuum stainless-steel oven. The experimental device has been already 176 described in detail in a previous work ${ }^{59}$. He $(0.5$ bar $)$ was flowed across the oven to carry the 177 PAH vapor before expansion through a $70 \mu \mathrm{m}$ nozzle to form a molecular beam which crossed 178 the two consecutive skimmers of the multipurpose SAPHIRS chamber ${ }^{60}$ before reaching the 179 ionization region. The temperature of the oven has been adjusted according to each CP-PAHs to 180 generate a vapor pressure enabling the recording of PES with Signal-To-Noise ratio SNR>3. 
181 Table 1 shows the working temperatures and consumption of the four compounds studied in this

182 work. The temperatures of the nozzle and oven were optimized to get around 6000 events/second 183 at the highest scan energy, which resulted in high quality scans with minimal consumption.

184

\begin{tabular}{|c|c|c|c|c|c|}
\hline $\mathbf{m} / \mathbf{z}$ & $\begin{array}{c}\text { Molecular } \\
\text { formula }\end{array}$ & Compound & Structure & $\begin{array}{c}\text { Temperature of oven / } \\
\text { nozzle }\left({ }^{\circ} \mathbf{C}\right)\end{array}$ & $\begin{array}{c}\text { Total } \\
\text { consumption (mg) }\end{array}$ \\
\hline 152 & $\mathrm{C}_{12} \mathrm{H}_{8}$ & Acenaphthylene & & $53 / 63$ & 60 \\
\hline 154 & $\mathrm{C}_{12} \mathrm{H}_{10}$ & Acenaphthene & & $55 / 65$ & 50 \\
\hline 202 & $\mathrm{C}_{16} \mathrm{H}_{10}$ & Fluoranthene & & $120 / 130$ & 1215 \\
\hline 226 & $\mathrm{C}_{18} \mathrm{H}_{10}$ & Benzo(ghi)fluoranthene & & $120 / 135$ & 12 \\
\hline
\end{tabular}

185

186

187

188

189

190

191

192

193

194

Table 1: Experimental conditions for PES and PIE curves measurements

The undulator-based DESIRS beamline ${ }^{61}$ was set to provide $\sim 5 \times 10^{12}$ photons $/ \mathrm{sec}$ with a spectral bandwidth of $10 \mathrm{meV}$ at $10 \mathrm{eV}$. A pressure of $0.14 \mathrm{mbar}$ of $\mathrm{Kr}$ filled the gas filter to ensure spectral purity in our energy range ${ }^{62}$ by suppressing the high harmonics of the undulator. The energy scales were absolutely calibrated using either the $4 \mathrm{p}^{5} 5 \mathrm{~s}(3 / 2) \mathrm{Kr}$ absorption line ${ }^{63}$ from the gas filter, as visible in the total ion yields, or the third-order ionization energy of He as reported in the NIST database. The energy scan data have been normalized by the photon flux measured with an AXUV100 photodiode from International Radiation Detectors, Inc.

The DELICIOUS3 i $^{2}$ PEPICO spectrometer ${ }^{64}$, which couples a VMI spectrometer on the electron side and a 3D-momentum imager spectrometer on the ion side, was used in the coincidence mode to obtain the photoelectron images correlated to a given ion mass and position at each scan point (or fixed photon energy), with a continuous extraction field of $88 \mathrm{~V} / \mathrm{cm}$. Note that the selection of a given ion arrival position in the detector (ion Region Of Interest, or ion ROI) ensures that only molecules originated in the flame or from HAP vaporization, and thus 
201 having a net velocity along the molecular beam, are considered, decreasing the background 202 signal coming from the $10^{-7}$ mbar base pressure of the ionization chamber ${ }^{65}$. TPES were obtained 203 with the Slow Photoelectron Spectroscopy method described previously ${ }^{66}$. For the standards 204 mentioned in Table 1, photoelectrons from 0 to $70 \mathrm{meV}$ were used to build the TPES, which 205 provided an electron kinetic energy resolution of $10 \mathrm{meV}$ as measured on the third-order 206 ionization of He, leading to an overall resolution of $14 \mathrm{meV}$ and an overall absolute accuracy for 207 the $I E$ determination of $0.003 \mathrm{eV}$.

\subsection{Flame sampling experiment}

A schematic representation of the experimental setup used for this work is reported in fig. 1 .

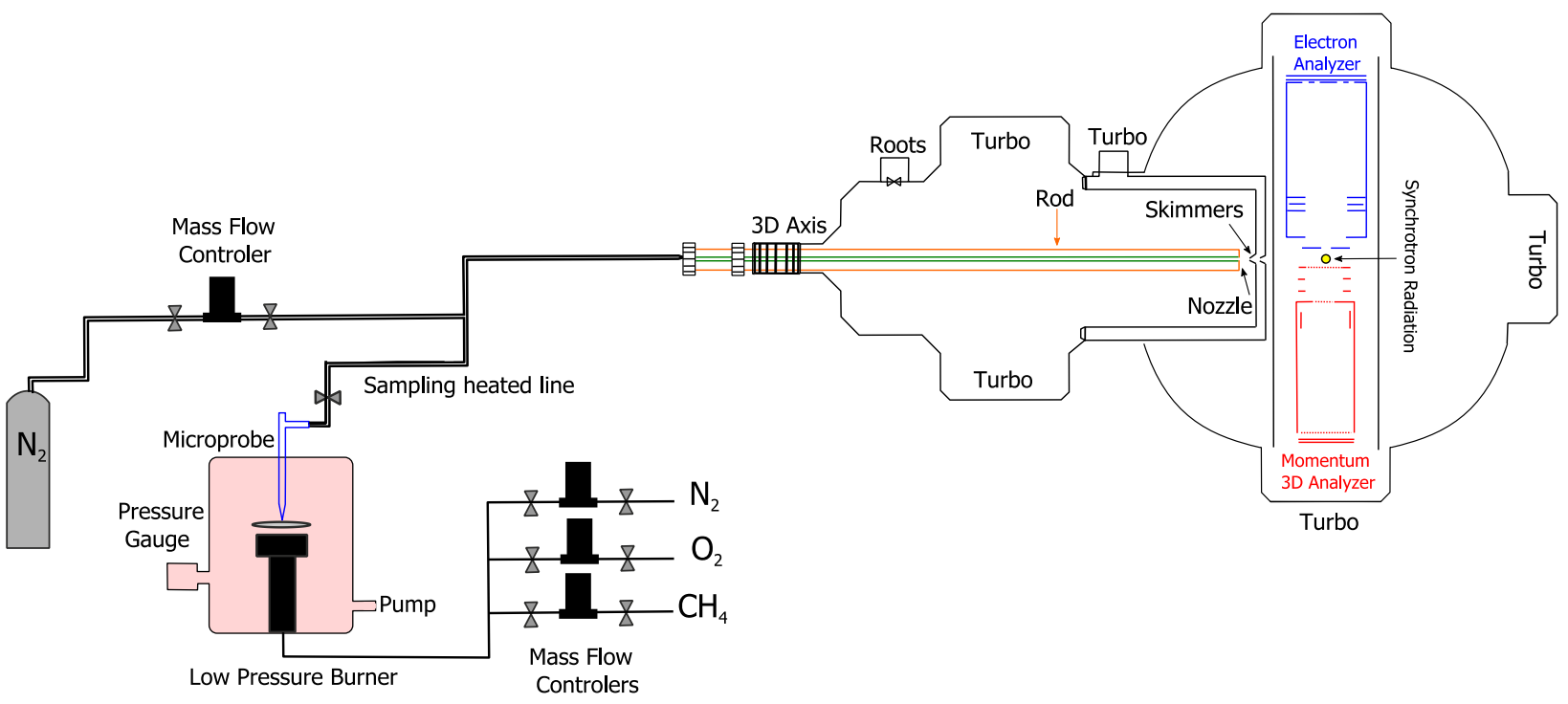

Figure 1: Experimental Setup

As mentioned in the introduction, we investigated a low pressure premixed sooting flame of methane/oxygen/nitrogen characterized by a fuel-to-oxidizer equivalence ratio $\phi=2.32$. The pressure inside the vessel was controlled and kept constant at $26.66 \mathrm{kPa}$ (200 torr) thanks to an automatic pressure regulation valve. More details about this flame and the low pressure vessel 218 arrangement can be found in previous publications ${ }^{25,26}$. The experimental flame conditions are 


\begin{tabular}{ccccc}
\hline$\phi$ & $\mathrm{C} / \mathrm{O}$ & $x_{\mathrm{CH}_{4}}$ & $x_{O_{2}}$ & $x_{N_{2}}$ \\
\hline \hline 2.32 & 0.58 & 0.462 & 0.398 & 0.14 \\
\hline
\end{tabular}

During the flame experiments, species were continuously extracted from the flame through a thin microprobe having a $300 \mu \mathrm{m}$ aperture diameter. The pressure inside the line was kept constant to $10 \pm 0.01$ mbar. The whole transfer line from the microprobe down to the skimmer located in the SAPHIRS chamber was heated up to $140{ }^{\circ} \mathrm{C}$ to limit the condensation of the PAHs as discussed in a previous work ${ }^{67}$. Extracted species were directly expanded in the SAPHIRS chamber through a nozzle with an orifice aperture of $500 \mu \mathrm{m}$. This relatively large orifice was used to optimize the SNR and the sensitivity of the measurement at the cost of a less efficiently cooled and collimated supersonic beam. The supersonic beam was then double skimmed before finally crossing the synchrotron beam at a right angle in the ion source of the $i^{2}$ PEPICO spectrometer. The position of the nozzle with respect to the ionization beam was aligned and optimized by using a dedicated $\mathrm{N}_{2}$ line.

With this setup, we implicitly made the choice to limit the detection to stable species only. Indeed, the use of a microprobe, instead of a sampling cone and skimmer device as usually implemented for generating a molecular beam, does not allow the capture of radicals. In return, this system offers a much lower detection limit than typical molecular beam mass spectrometry setups. We estimated our detection limit in the order of $0.1 \mathrm{ppm}$, i.e. at least one order of magnitude lower than the typical sensitivity of 1-10 ppm of molecular beam mass spectrometry setups reported in the literature ${ }^{31,32,68,69}$. This value was estimated from the comparison with quantitative measurements carried out by JCLIF in the same flame ${ }^{25}$ reporting peak mole fractions of pyrene and fluoranthene around 0.4 and $0.1 \mathrm{ppm}$. 
In this work, we carried out either the recording of ion mass- and ROI-selected PES data at

244 fixed photon energy (denoted as PES spectra in figures) and/or TPES spectra by scanning the 245 photon energy ${ }^{66}$. PES typically required around 30 minutes of data acquisition to get a 246 satisfactory SNR (typically SNR>3). The TPES mode greatly improves the spectral resolution 247 but requires an acquisition of a few hours because the photon energy needs to be scanned. For 248 the flame experiments, the photoelectron window used to obtain the TPES was increased to 200 $249 \mathrm{meV}$ to achieve a better SNR, leading to an overall energy resolution of $35 \mathrm{meV}$.

250 Most PES experiments were performed at $8 \mathrm{eV}$ to favor the ionization of small PAHs and 251 limit fragmentation of the parent cations. However, we also report a few spectra recorded at 252 higher $I E$ up to $9-10 \mathrm{eV}$, in order to broaden the range of detected species towards small 253 aromatic and aliphatic compounds.

254 As mentioned above, we focused our measurements on the beginning of the soot nucleation 255 zone of the flame as determined in previous work $^{25,54}$, which corresponds to a region located 256 from height above the burner (HAB) 9 to $15 \mathrm{~mm}$ where the temperature of the flame has been 257 determined be nearly constant around $1760 \pm 20 \mathrm{~K}^{52}$. Note that around 80 different peaks in the $258 \quad 40-252 \mathrm{~m} / \mathrm{z}$ range have been detected in this zone.

\section{Results and discussion}

\subsection{Measurements of the reference PES and PIE curves of acenaphthene,} acenaphthylene, fluoranthene and benzo(ghi)fluoranthene

The TPES and PIE curves recorded for the four CP-PAHs are shown in fig.2. Note that all the data shown correspond to the parent ion selection. No fragmentation channels have been identified in the TOF mass spectra for any of the four PAHs considered here, up to $10.5 \mathrm{eV}$. 
268 and fluoranthene ${ }^{37}$, the hereby reported TPES for these species correspond to new and unique 269 reference spectra to the best of our knowledge. Concerning benzo(ghi)fluoranthene, neither $I E$ 270 values nor PES or PIE curves were available in the literature. Note that the SNR is inferior in this 271 last spectrum than in the other ones due to the much lower vapor pressure of 272 benzo(ghi)fluoranthene. However, the recorded spectrum still highlights clearly distinguishable 273 and characteristic vibronic structures. Such spectra are likely to be used for the identification of 274 these species in various applications including combustion but also other scientific fields like 275 astrophysics. The unique character of these new data remains therefore of significant interest 276 beyond the scope of combustion studies. Notably, the spectrum of fluoranthene, which is a 277 structural isomer of pyrene, potentially remains of great interest for both these communities 278 considering the importance of pyrene in rich flame chemistry and interstellar medium. Although 279 pyrene itself has not yet been discovered in any interstellar media, PAHs and PAH cations 280 remain very astrophysically relevant. Kim et al. $^{70}$ reported that the infrared spectrum of the 281 pyrene cation very closely resembles the interstellar unidentified infrared emission bands. 282 Furthermore, this work also opens a new way to individually identify these PAHs in interstellar 283 ice analogs and carbonaceous chondrites ${ }^{71,72}$. 

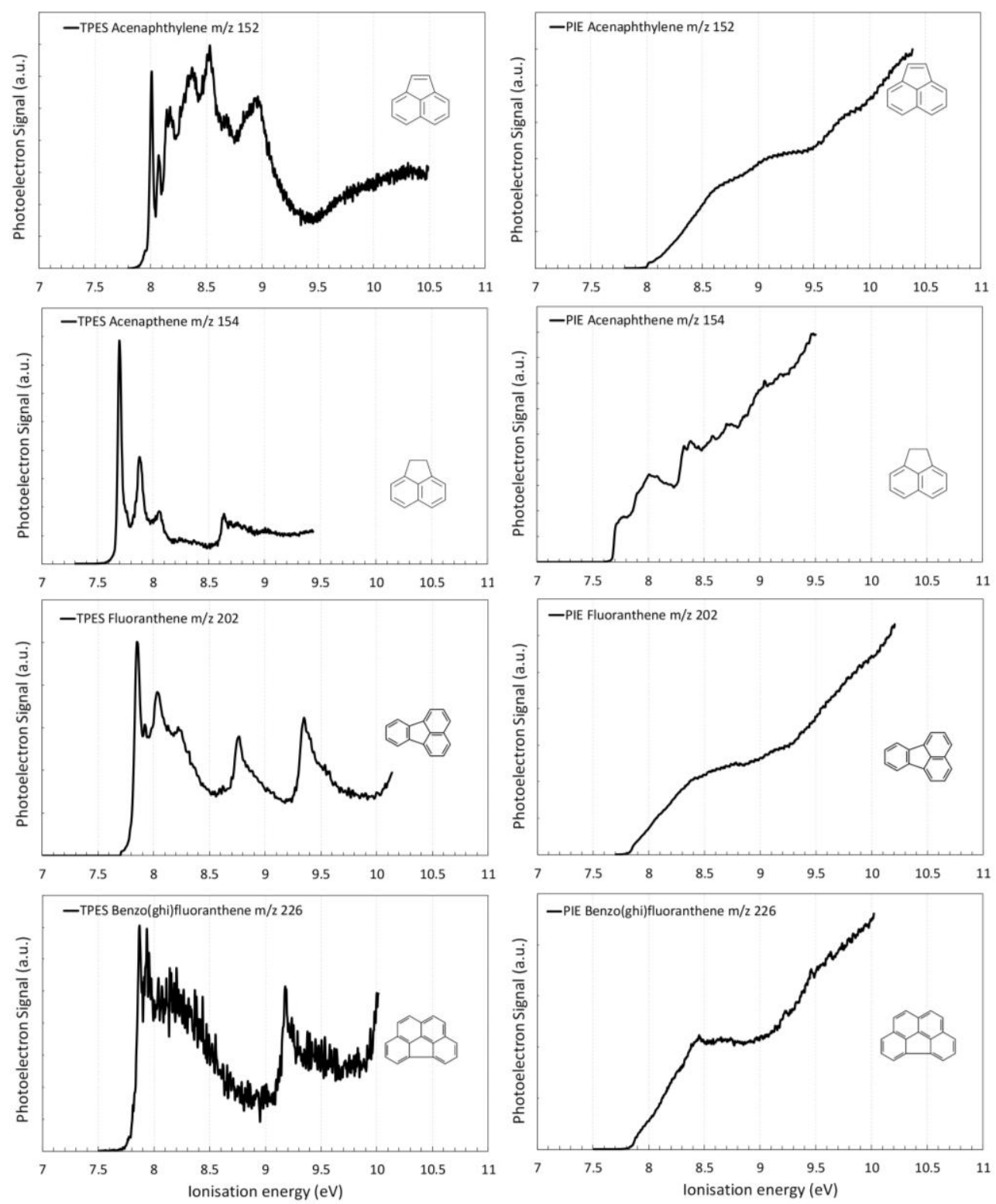

Figure 2: TPES (left column) and PIE curves (right column) of the four studied PAHs

The four measured TPES show strong distinguishable spectral features from which it is possible to extract the corresponding adiabatic ionization energy $\left(I E_{\mathrm{ad}}\right) . I E_{\mathrm{ad}}$ values are important as they are widely used to identify structural isomers in VUV-photoionization mass spectrometry

291 experiments. In this work, the experimental $I E_{\mathrm{ad}}$ have been measured by fitting a Gaussian peak 292 to the first transition of each spectrum, which is also the most intense band, meaning that there is 293 little geometric change of the molecular structure upon ionization (favorable FC factors), which 294 is typical of $\mathrm{PAHs}^{38,73,74}$. The determined values, from the maximum of the Gaussian fitting 
295 function, are reported in the first column of table 3 and compared to measured values provided 296 by the literature and referenced in the NIST Webbook. Note that for the three components for 297 which $I E_{\text {ad }}$ was previously known, our data provides an increased accuracy on the values. 298

\begin{tabular}{|c|c|c|c|c|c|c|c|c|}
\hline \multirow{4}{*}{$\begin{array}{r}\mathbf{m} / \mathbf{z} \\
\\
152\end{array}$} & \multirow{4}{*}{$\begin{array}{c}\text { Molecular } \\
\text { formula } \\
\mathrm{C}_{12} \mathrm{H}_{8}\end{array}$} & \multirow{4}{*}{\begin{tabular}{|l} 
Compound \\
Acenaphthylene
\end{tabular}} & \multirow{2}{*}{\multicolumn{6}{|c|}{$I E_{\text {ad }}(\mathbf{e V})$}} \\
\hline & & & & & & & & \\
\hline & & & \multirow{2}{*}{\begin{tabular}{|l} 
This work \\
$8.012 \pm 0.003$
\end{tabular}} & \multicolumn{5}{|c|}{ Literature } \\
\hline & & & & $8.02 \pm 0.04^{\mathrm{a}}$ & $8.22 \pm 0.01^{b}$ & & & \\
\hline 154 & $\mathrm{C}_{12} \mathrm{H}_{10}$ & Acenaphthene & $7.700 \pm 0.003$ & $7.68 \pm 0.05^{\mathrm{c}}$ & $7.73 \pm 0.01^{\mathrm{b}}$ & $7.66^{\mathrm{d}}$ & $7.76 \pm 0.03^{\mathrm{e}}$ & $7.82 \pm 0.04^{2}$ \\
\hline 202 & $\mathrm{C}_{16} \mathrm{H}_{10}$ & Fluoranthene & $7.860 \pm 0.003$ & $7.90 \pm 0.1^{\mathrm{f}}$ & $7.95 \pm 0.04^{\mathrm{a}}$ & $7.80 \pm 0.01^{\mathrm{b}}$ & $7.72^{\mathrm{g}}$ & \\
\hline 226 & $\mathrm{C}_{18} \mathrm{H}_{10}$ & Benzo(ghi)fluoranthene & $7.874 \pm 0.003$ & & & & & \\
\hline
\end{tabular}

Table 3: Determined first adiabatic ionization energy compared to referenced values ${ }^{37}$

As can be seen in table 3, although for the most part our data agree with the literature values 305 within the uncertainty, differences in $I E_{\mathrm{ad}}$ of more than $100 \mathrm{meV}$ can be observed, which show 306 potential deficiencies in the existing databases and the need of upgrading these values to meet 307 the requirements of modern analytical experiments, especially in the context of species 308 identification in complex mixtures.

309 Beyond the $I E$ values, the overall shape of the TPES is relevant for the analysis of combustion 310 processes, especially for the ground electronic state (typically over the first 1-1.5 eV above $I E_{\text {ad }}$ ). 311 Without entering into a detailed analysis, which is beyond the scope of this work, the FC 312 envelope of the ground electronic state of the four species shows quite a rich vibrational structure 313 which is a molecular fingerprint for the analysis of complex mixtures. As discussed above, TPES 
314 fingerprints are much sharper and molecule-specific than the PIE step functions (especially for

315 acenaphthylene and fluoranthene) and are therefore more appropriate as reference functions for

316 fitting the experimental data obtained from the analysis of complex mixtures. flames

Figure 3 shows a zoom of the mass spectra recorded at a fixed photon energy of $8 \mathrm{eV}$ and for three distinct sampling $\operatorname{HABs}(9,12$ and $15 \mathrm{~mm}$ above the burner) corresponding to the
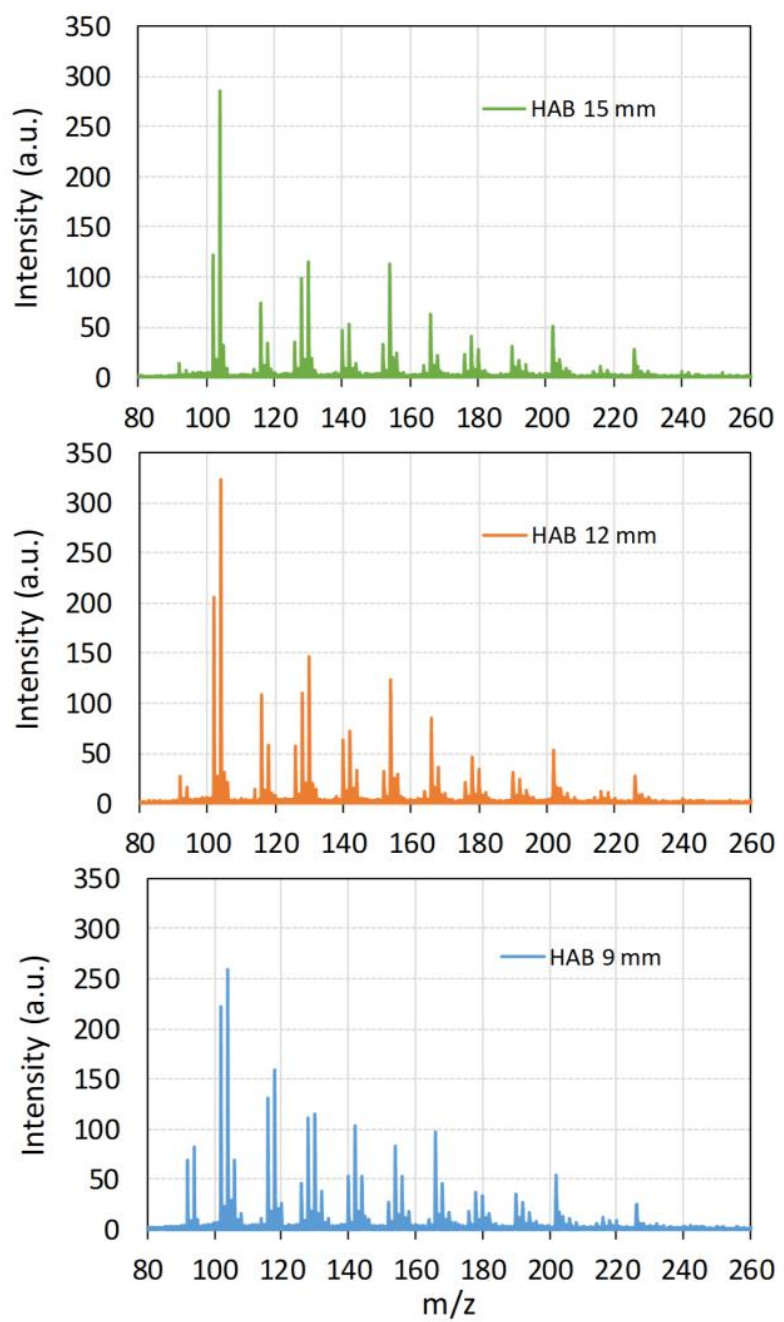

Figure 3: Zoom of the mass spectrum of the flame acquired at photon energy $8 \mathrm{eV}$ 
Some peaks consistent to CP-PAHs and side-substituted PAHs can be noted in fig. 3 at 152 $m / z\left(\mathrm{C}_{12} \mathrm{H}_{8}\right), 154 \mathrm{~m} / z\left(\mathrm{C}_{12} \mathrm{H}_{10}\right), 166 \mathrm{~m} / z\left(\mathrm{C}_{13} \mathrm{H}_{10}\right), 190 \mathrm{~m} / \mathrm{z}\left(\mathrm{C}_{15} \mathrm{H}_{10}\right), 202 \mathrm{~m} / z\left(\mathrm{C}_{16} \mathrm{H}_{10}\right), 216 \mathrm{~m} / \mathrm{z}$ $\left(\mathrm{C}_{17} \mathrm{H}_{12}\right), 226 \mathrm{~m} / \mathrm{z}\left(\mathrm{C}_{18} \mathrm{H}_{10}\right)$, and $252 \mathrm{~m} / z\left(\mathrm{C}_{20} \mathrm{H}_{12}\right)$. As mentioned above, the exhaustive analysis of all detected masses is beyond the scope of this work, and here we focus on those for which this study can offer the most interesting methodological and mechanistical information, as discussed below.

To this end, the remaining of this section is organized in two main parts. The first one is dedicated to the implementation of the $i^{2}$ PEPICO setup for the identification of small aromatic species well known to be formed in sooting flames. The objective of this first part is to check the performance of the $i^{2} \mathrm{PEPICO}$ apparatus for this relatively new task in the context of sooting flames studies. In the second part, we focus on the study of four different detected masses in our flame, expected to correspond to moderate-sized PAHs that are very likely involved in the soot formation mechanisms. These species correspond to $152 \mathrm{~m} / \mathrm{z}\left(\mathrm{C}_{12} \mathrm{H}_{8}\right), 154 \mathrm{~m} / \mathrm{z}\left(\mathrm{C}_{12} \mathrm{H}_{10}\right), 202 \mathrm{~m} / \mathrm{z}$ $\left(\mathrm{C}_{16} \mathrm{H}_{10}\right)$ and $226 \mathrm{~m} / \mathrm{z}\left(\mathrm{C}_{18} \mathrm{H}_{10}\right)$.

The identification method we used relies on the analysis of spectral structures of the experimental TPES measured at different $\mathrm{HAB}$ in the nucleation region of the flame. The identification of the species corresponding to the measured spectral structure is carried out by 344 comparing reference PES of individual PAHs (provided by the literature or from this work) with 345 the one acquired in the flame experiments. To perform these comparisons, it has been necessary 346 to adjust the spectral resolution of the reference spectra when they were recorded with a better 347 spectral resolution than the experimental spectra. This has been carried out by convolving the 348 reference spectra provided by the literature to a Gaussian function to enlarge the spectral 349 structures of these spectra. The shape of the Gaussian function has been systematically adjusted 350 according to the resolution of the reference spectra, which came from different sources, in order 351 to get the best match with our experimental spectral structures. 


\subsubsection{Analysis of the species at $78 \mathrm{~m} / z\left(\mathrm{C}_{6} \mathrm{H}_{6}\right)$}

Benzene is a species of great interest for soot formation as it plays a major role in the initiation of the HACA mechanism. However, benzene is not the only isomer possibly detected in sooting flames at $78 \mathrm{~m} / \mathrm{z}$. Fulvene, which has already been observed in rich flames ${ }^{82}$, is another likely candidate that has been taken into account to analyze this spectrum. The measured TPES and PES corresponding to $78 \mathrm{~m} / \mathrm{z}$ are reported in fig. $\mathbf{4 a}$ and $\mathbf{4 b}$. The simulated spectrum (black line), calculated on the basis of the reference spectra of benzene ${ }^{83}$ (grey dotted line) and fulvene $^{84}$ (grey dashed line), is also reported on these figures. Due to the poorer spectral resolution of the PES in comparison with the TPES, we intentionally degraded the simulated spectrum reported in fig. $4 \boldsymbol{b}$ using the procedure described by Felsmann et al. ${ }^{41}$ for previous comparable analyses. The PES has been measured with the sampling probe in the sooting flame positioned at $\mathrm{HAB}=12 \mathrm{~mm}$, at a fixed photon energy of $10 \mathrm{eV}$. This is the reason why the PES appears truncated, reaching a zero value at $10 \mathrm{eV}$.

The acquisition time for this PES was approximately 30 minutes. The TPES reported in fig. $4 \boldsymbol{a}$ required the fine scanning of the ionization energy from 7.2 to $10 \mathrm{eV}$ with a step of $0.04 \mathrm{eV}$. This relatively large step has been chosen to limit the acquisition time to 6 hours. Both TPES and PES clearly show an intense peak at $9.23 \mathrm{eV}$, in excellent agreement with the $I E$ value of $9.24 \mathrm{eV}$ of the $0-0$ vibrational transition of benzene reported in the literature ${ }^{85}$, followed by a series of less intense vibrational progressions. Also visible in these spectra, especially the TPES, is a series of weak spectral features between 8.3 and $9.0 \mathrm{eV}$ before the occurrence of the first benzene peak. This structure is in good agreement with the vibrational structure of the electronic ground state of fulvene characterized by two main peaks at $8.36 \mathrm{eV}$ and $8.52 \mathrm{eV}^{85}$. The best adjustment we found between the experimental spectrum (orange line) and the simulated one (black lines) in fig. 4 has been obtained for relative contributions of benzene and fulvene of $90 \%$ and $10 \%$, respectively. This analysis therefore provides clear evidence of the formation of benzene in the 
nucleation zone of the flame, in competition with fulvene with a much lower apparent signal ratio. This information is however less explicit in the PES reported in fig. $4 \boldsymbol{b}$ due to the choice of the ionization energy which truncates the higher binding energy part of the spectrum.
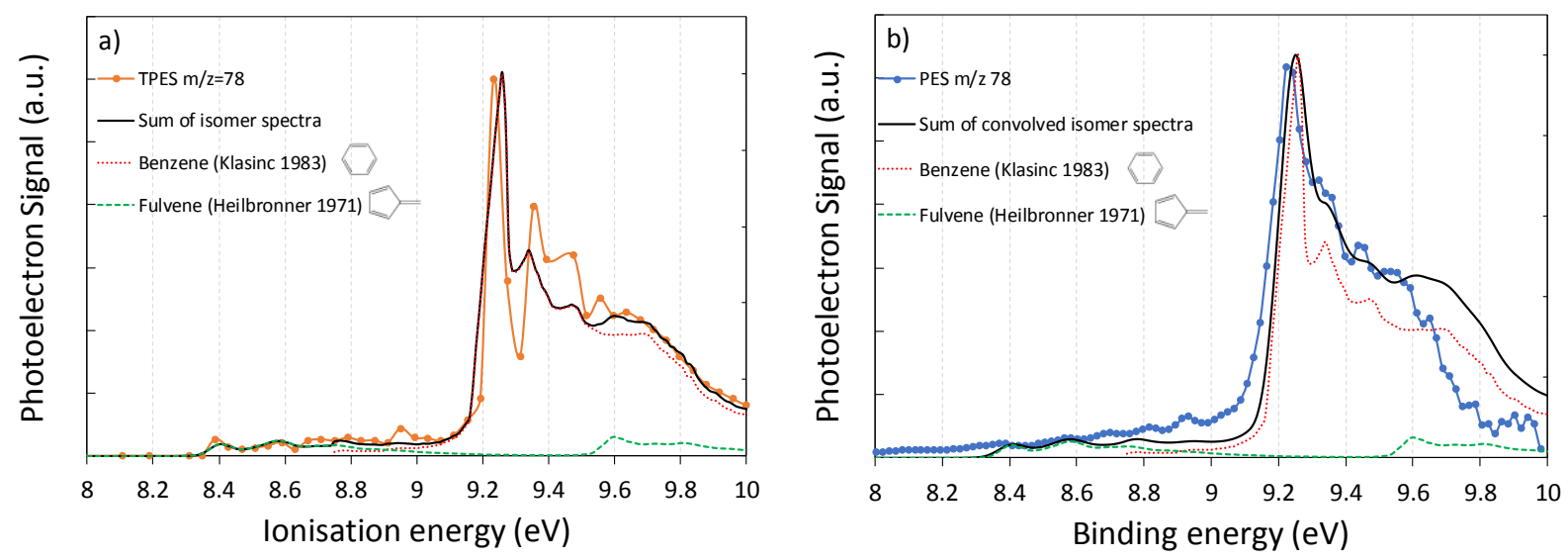

Figure 4: TPES and PES (recorded at $10 \mathrm{eV}$ ) of $78 \mathrm{~m} / \mathrm{z}$ at $\mathrm{HAB}=12 \mathrm{~mm}$.

It is to be noted that, in a previous study, the mole fraction of benzene was determined around $85 \mathrm{ppm}$ at this $\mathrm{HAB}$ in this flame by $\mathrm{JCLIF}^{26}$. Based on this experimental value, the concentration of fulvene can be determined from the relative intensities of the two spectra and the knowledge of the ionization cross section at $10 \mathrm{eV}$. Hence the mole fraction of fulvene $\mathrm{X}_{\mathrm{f}}$ can be related to the benzene mole fraction $\mathrm{X}_{\mathrm{b}}$ according to the formula:

$$
\mathrm{X}_{f}=\mathrm{X}_{b} \frac{\sigma_{i b}}{\sigma_{i f}} \frac{S_{f}}{S_{b}}
$$

391 where $\sigma_{i b}$ and $\sigma_{i f}$ correspond to the benzene and fulvene ionization cross sections at $10 \mathrm{eV}$ and $392 \mathrm{~S}_{\mathrm{f}} / \mathrm{S}_{\mathrm{b}}$ corresponds to the relative signal ratio of the contributions of fulvene and benzene. The 393 absolute cross-section of benzene at $10 \mathrm{eV}$ has been measured at $25 \mathrm{Mb}^{86,87}$, while for the 394 fulvene only an estimated value of $35 \mathrm{Mb}$ is found in the literature ${ }^{88}$. These values lead to an 395 estimated mole fraction of fulvene around $7 \mathrm{ppm}$ at $12 \mathrm{~mm} \mathrm{HAB}$. 
Note that the PES, which requires 12 times less time than the recording of the TPES scan, still provides an adequate resolution and sensitivity for the detection of benzene in these conditions, with the added advantages of not needing a stable sample, or tunable light, as discussed by Krüger et $a l .{ }^{43}$ However, the degraded spectral resolution renders the identification of fulvene somewhat less certain.

401

\subsubsection{Analysis of the species at $116 \mathrm{~m} / z\left(\mathrm{C}_{9} \mathrm{H}_{8}\right)$}

This peak, commonly detected in sooting flames, potentially corresponds to indene, i.e. the lightest CP-PAHs consisting of one six-member and one five-member ring. The identification of this species by mass spectrometry methods is not trivial because of the several isomers coexisting at this $\mathrm{m} / \mathrm{z}$, the most important of which being 1-propynylbenzene and the three ethynyl-methyl-benzenes ${ }^{31,41}$. IEs of $8.14 \mathrm{eV}^{76}$ and $8.41 \mathrm{eV}^{89}$ have been reported for indene and 1-propynylbenzene respectively, while the $I E$ values of 1-ethynyl-4-methylbenzene, 1-ethynyl-3methylbenzene and 1-ethynyl-2-methylbenzene are $8.48,8.63$ and $8.61 \mathrm{eV}^{89}$. We show in fig. $5 \boldsymbol{a}$ $\boldsymbol{a n d} \boldsymbol{5} \boldsymbol{b}$ the comparison of experimental TPES and PES obtained at HAB $=15 \mathrm{~mm}$ with reference 411 spectra for pure indene and 1-propynylbenzene ${ }^{90}$. As in the case of benzene detection, the TPES 412 in fig. $5 \boldsymbol{a}$ required a 6 hours long scan while the PES reported in $\boldsymbol{f i g} . \mathbf{5} \boldsymbol{b}$ has been recorded with a much shorter acquisition time of approximately 30 minutes. The spectral resolution of both

414 reference spectra has been adjusted in order to match our experimental conditions. This has been 415 done by convolving the reference spectra with a Gaussian function according to the protocol 416 previously described in Felsmann et al. ${ }^{41}$

417 Although the TPES of indene reported in fig. 5a seems in itself able to explain our spectrum, 418 we also considered the potential contribution of the only other isomer for which the TPES has 419 been reported, 1-propynylbenzene. The indene and 1-propynylbenzene contributions associated 420 to the simulated spectra have been found to be $83 \%$ and $17 \%$, respectively. However, it is 
possible that minor contributions of other structural isomers are present on this spectrum. We

422 notably observe a slight increase in signal around $8.5 \mathrm{eV}$ which might highlight the presence of 423 1-ethynyl-4-methylbenzene, a species for which no reference spectrum is currently available. 424 Moreover, no correspondence could be found either for the small spectral features between 7.6 425 and $8.0 \mathrm{eV}$, the lowest IE reported in the literature for $116 \mathrm{~m} / \mathrm{z}$ being the one of indene ${ }^{91}$.
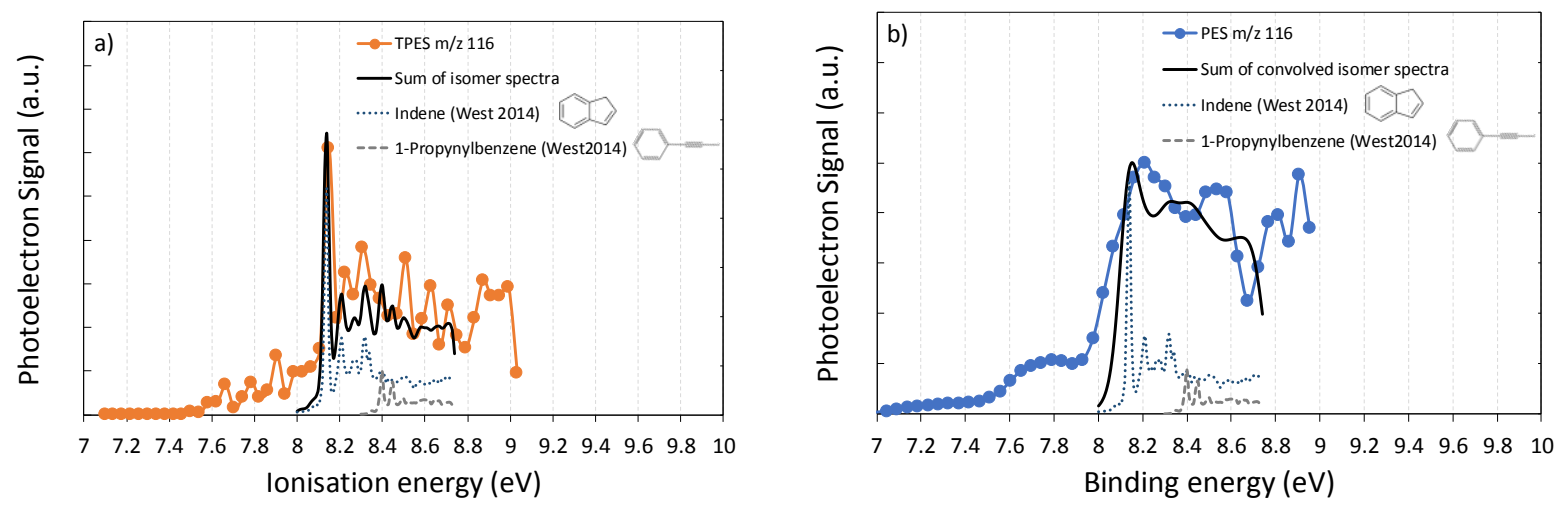

Figure 5: TPES (recorded at $10 \mathrm{eV}$ ) and PES of $116 \mathrm{~m} / \mathrm{z}$ at $\mathrm{HAB}=15 \mathrm{~mm}$.

Comparison with a simulated spectrum (in black) corresponding to the sum of reference PES of indene and 1-

Our experimental PES in fig. $5 \boldsymbol{b}$ shows a very similar structure to the one reported by 435 Felsmann et al. ${ }^{41}$. In this previous work, the $116 \mathrm{~m} / \mathrm{z}$ signal was also studied with the same setup 436 at SOLEIL, but in a low-pressure, rich flame of cyclopentene ( $\phi=1.70, p=33.3 \mathrm{mbar})$ and using a molecular beam mass spectrometry configuration for the sampling of the species. The PES 438 structure highlights a strong feature in excellent agreement with the $I E_{\mathrm{ad}}$ value of $8.14 \mathrm{eV}$ of 439 indene $^{76}$, which allows its clear identification from this spectrum. Concerning 440 1-propynylbenzene, its lower concentration in comparison with indene combined with the low 441 spectral resolution of the PES make its identification less evident from this spectrum. It is 
442 interesting to note that the analysis of this mass is in good agreement with previous similar 443 experiments ${ }^{41}$.

444 Finally, the experimental TPES reported in fig.5a shows a much better spectral resolution and 445 agreement with the sum of indene and 1-propynylbenzene spectra. As for the case of $78 \mathrm{~m} / \mathrm{z}$, we 446 however note some slight differences in this PES/TPES comparison which can mainly be 447 attributed to the degraded SNR of our experiment because of the relatively weak concentration 448 of these species. The mole fraction of indene has been estimated by modeling to be around $0.5 \mathrm{ppm}$ in the flame ${ }^{52}$. Hence, we can state that the TPES allows an accurate identification of indene in this flame while the identification of the signal around $8.40-8.50 \mathrm{eV}$ to 1 451 propynylbenzene still needs confirmation.

\subsubsection{Analysis of the species at $128 \mathrm{~m} / \mathrm{z}\left(\mathrm{C}_{10} \mathrm{H}_{8}\right)$}

TPES and PES measured at $\mathrm{HAB}=15 \mathrm{~mm}$ and corresponding to $128 \mathrm{~m} / \mathrm{z}$ are reported in fig.
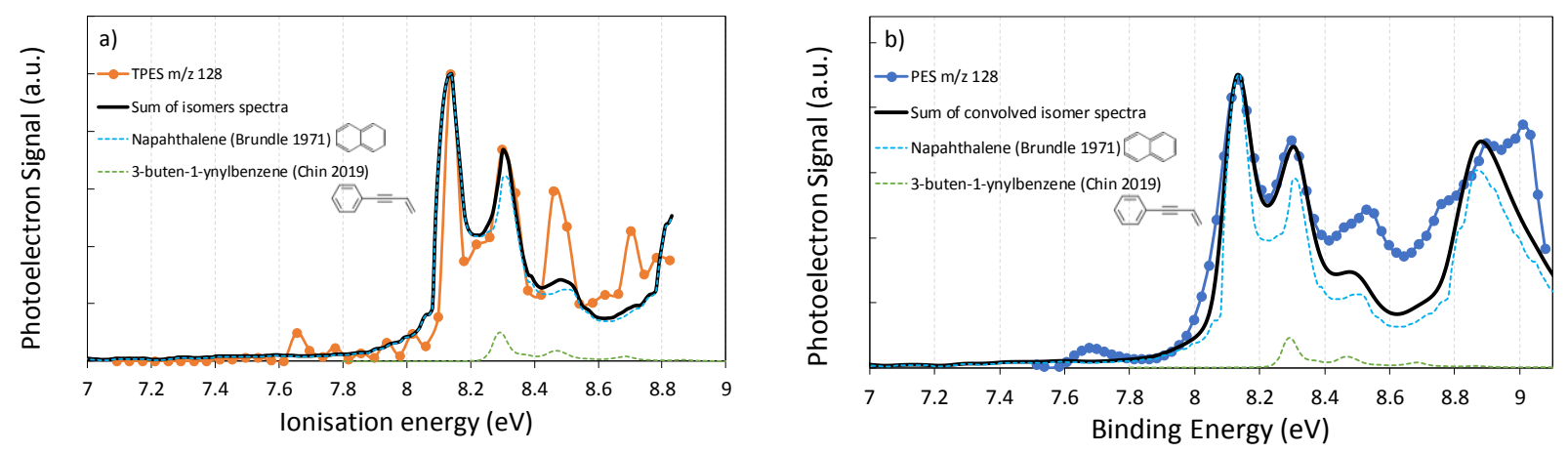

Figure 6: TPES and PES of $128 \mathrm{~m} / \mathrm{z}$ at $\mathrm{HAB}=15 \mathrm{~mm}$.

Comparison with a simulated spectrum (in black) corresponding to the sum of reference PES of naphthalene and 
The TPES shows an intense peak, which is in perfect agreement with the value of the first $I E$ potential of naphthalene of $8.14 \mathrm{eV}^{37}$. Moreover, the experimental spectrum also features a vibrational structure characterized by two other weaker spectral bands peaking around 8.30 and $8.50 \mathrm{eV}$, also in good agreement with the naphthalene reference spectrum ${ }^{92}$. The PES in fig. $\boldsymbol{6} \boldsymbol{b}$ also provides an adequate resolution for the identification of naphthalene sampled from the flame. The first three peaks of the vibrational structure of naphthalene are clearly visible in the PES as well (fig. $\boldsymbol{6} \boldsymbol{b})$. In addition, the spectrum shows a strong band at $8.85 \mathrm{eV}$ which is also indicative of naphthalene. It should be noted that we again intentionally degraded the resolution of the reference spectrum to match the experimental condition of the PES.

In both PES and TPES, two spectral regions of the experimental spectra do not match the reference naphthalene spectrum. The first spectral region is characterized by a weak spectral 475 feature peaking around $7.65 \mathrm{eV}$ for which we could not find any potential candidate with such a low $I E$ value. Only azulene, with a first $I E_{\text {ad }}$ around $7.42 \mathrm{eV}$, might be responsible for these

477 structures $^{93}$, but neither its $I E_{\text {ad }}$ nor its vibronic structure match our spectrum, so that this species 478 can safely be excluded from the list of potential candidates.

479 The second spectral region not perfectly reproduced by the reference spectrum of naphthalene 480 is between 8.4 and $8.7 \mathrm{eV}$. This part of the spectrum notably displays a significant peak around $4818.5 \mathrm{eV}$, which potentially originates from another isomer. Again, we could not find any 482 compound matching this $I E$ value. Chin et al. ${ }^{94}$ recently reported simulated PES of some 483 naphthalene isomers from their Franck-Condon calculations. The spectrum reported in green 484 dashed lines in fig. 6 corresponds to the calculated spectrum for 3-buten-1-ynyl benzene. This 485 minor contribution ( $10 \%$ of the naphthalene contribution) improves the fit of the experimental 486 spectra, but is not sufficient to completely explain the shape of the spectrum around $8.5 \mathrm{eV}$. A 487 shift of the 3-buten-1-ynyl benzene calculated spectrum by a few $100 \mathrm{meV}$ 's would improve the 488 correlation with $8.5 \mathrm{eV}$ measured feature in both the PES and TPES. 
This comparison clearly confirms naphthalene as the main compound at $128 \mathrm{~m} / \mathrm{z}$, the mole

490 fraction of which having been previously measured by JCLIF around 1-2 ppm in this region of 491 the flame ${ }^{67}$. The uncertainty on the identification of the potential other minor species highlights

492 the need for reference PES to facilitate the analysis of PAHs formed in sooting flames.

493 To conclude on these first measurements, we can state that the spectral resolution, selectivity 494 and sensitivity of the $i^{2}$ PEPICO apparatus enable the selective detection of PAHs structural 495 isomers. The TPES, while requiring longer acquisition times provided a more accurate 496 distinction between structural isomers when reference spectra are available, whereas the faster 497 recorded PES lead to a degraded spectral resolution and lower SNR in comparison with TPES 498 experiments. This can limit their usability for the determination of the contributions of minor 499 species, although they still provide richer information than PIE curves.

500 In the following sections, peaks for larger detected $\mathrm{m} / \mathrm{z}$ are investigated. The objective of this 501 further work is to reveal the potential formation of CP-PAHs and side-substituted PAHs, likely 502 involved in soot formation, besides the more commonly investigated benzenoid PAHs in the 503 detected species sampled from the nucleation zone of the flame.

\subsection{Identification of CP-PAHs and side-substituted PAHs in sooting flames}

To highlight the capabilities of the $\mathrm{i}^{2} \mathrm{PEPICO}$ method for the identification of PAH isomers, 507 further work focused on four detected species usually observed in sooting flames for which 508 structural isomers potentially involving CP-PAHs and side-substituted PAHs might be formed. 509 In the following, we systematically report the TPES recorded at the very beginning of the soot 510 inception zone $(\mathrm{HAB}=9 \mathrm{~mm})$, and well inside the flame soot nucleation region $(\mathrm{HAB}=15$ $511 \mathrm{~mm})$. The corresponding spectra have been determined with different energy steps $(0.01 \mathrm{eV}$ at $512 \mathrm{HAB}=9 \mathrm{~mm}$ and $0.04 \mathrm{eV}$ at $\mathrm{HAB}=15 \mathrm{~mm}$, requiring 10 and 4 hours of recording time, 513 respectively). 


\subsubsection{Analysis of the species at $152 \mathrm{~m} / z\left(\mathrm{C}_{12} \mathrm{H}_{8}\right)$}

This $m / z$ is frequently detected in the mass spectra of rich and lightly sooting flames. The

isomers commonly associated to this mass in the literature are 1-ethynylnaphthalene $(I E=8.03 \mathrm{eV})^{95}, \quad$ 2-ethynylnaphthalene $(I E=8.11 \mathrm{eV})^{95}$, biphenylene $(I E=7.56 \mathrm{eV})^{77}$ and acenaphthylene $(I E=8.02 \mathrm{eV})^{76}$. PIE curves are often used for the identification of these species.

However, the close ionization threshold values of these compounds do not allow the clear distinction of acenaphthylene and the two ethynylnaphthalene isomers.

The vibronic structure seen in the TPES reported in fig.7 provides much more precise information for the identification of these species. Fig. $7 \boldsymbol{a}$ shows the TPES measured at HAB $=$ $9 \mathrm{~mm}$ while fig. $7 \boldsymbol{b}$ shows the spectrum recorded at $\mathrm{HAB}=15 \mathrm{~mm}$. The TPES of pure acenaphthylene measured in this work (see fig.2) is shown alongside for comparison.
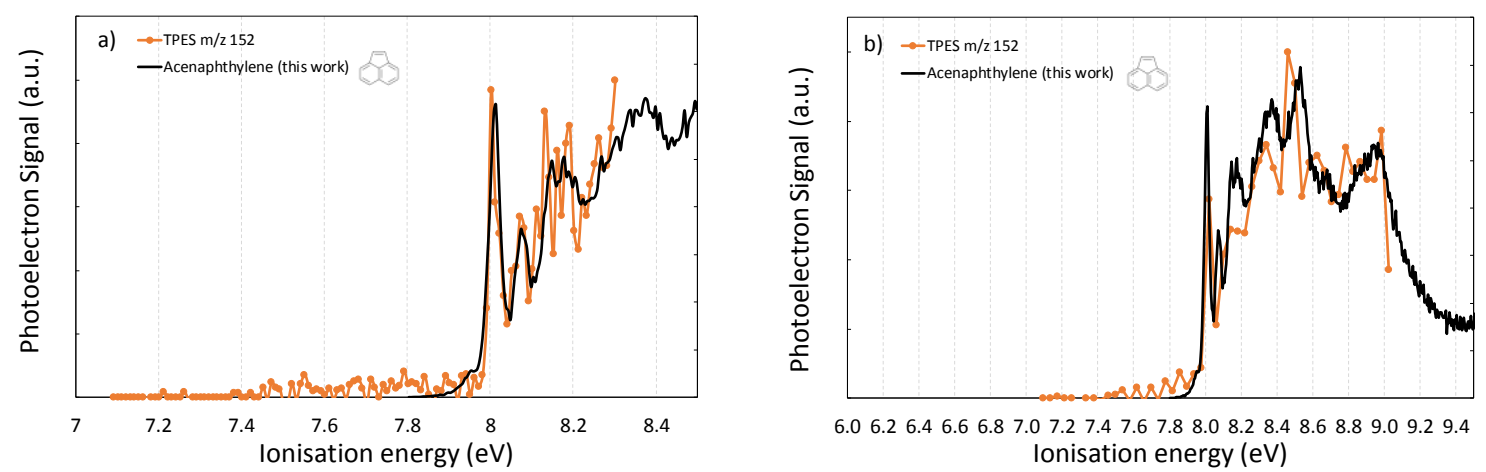

Figure 7: TPES of $152 \mathrm{~m} / \mathrm{z}$ at $\mathrm{HAB}=9$ and $15 \mathrm{~mm}$.

Comparison with reference TPES of acenaphthylene. detailed analysis because of its lower resolution. However, the first very narrow vibrational 
mode is still captured by the experiment and the recorded spectrum globally shows an excellent match with the overall shape of the pure acenaphthylene spectrum over this larger energy scale. These data clearly support acenaphthylene as the main species detected at $152 \mathrm{~m} / \mathrm{z}$ in the nucleation region of the flame.

\subsubsection{Analysis of the species at $154 \mathrm{~m} / \mathrm{z}\left(\mathrm{C}_{12} \mathrm{H}_{10}\right)$}

This mass is usually assigned, in rich flame studies reported the literature, to biphenyl $543(I E=8.16 \mathrm{eV})^{37}$ and acenaphthene $(I E=7.67 \mathrm{eV})^{37}$. We have reported in fig. $8 \boldsymbol{a}$ and fig.8b, the 544 TPES measured at $\mathrm{HAB}=9$ and $15 \mathrm{~mm}$. These two spectra are relatively noisy in comparison to 545 previous measurements at $152 \mathrm{~m} / \mathrm{z}$. Moreover, the global structure of both spectra $(\mathrm{HAB}=9$ and $54615 \mathrm{~mm}$ ) does not display any specific features as observed for other selected $\mathrm{m} / \mathrm{z}$, except a 547 moderate peak around $7.70 \mathrm{eV}$. The absence of such peculiar spectral features illustrates the 548 limitation of the TPEPICO method which may arise in some cases for the identification of 549 structural isomers. However, these limitations would be even more severe with the use of PIE 550 which would be totally featureless.

551 Hence, to interpret this spectrum, we first tried to reproduce it with a linear combination of 552 the two commonly considered isomers in flames at $154 \mathrm{~m} / \mathrm{z}$ (biphenyl and acenaphthene) without 553 success, meaning that some additional isomers were to be considered for this mass. However, we 554 note an interesting match between the experimental peak detected around $7.70 \mathrm{eV}$ and the first 555 vibrational mode of the reference spectrum of acenaphthene that we determined (see Fig.2). To 556 complete the overall structure of the simulated spectra, we checked in the literature ${ }^{37,96}$ for other 557 species corresponding to this mass, potentially formed in sooting flames. 

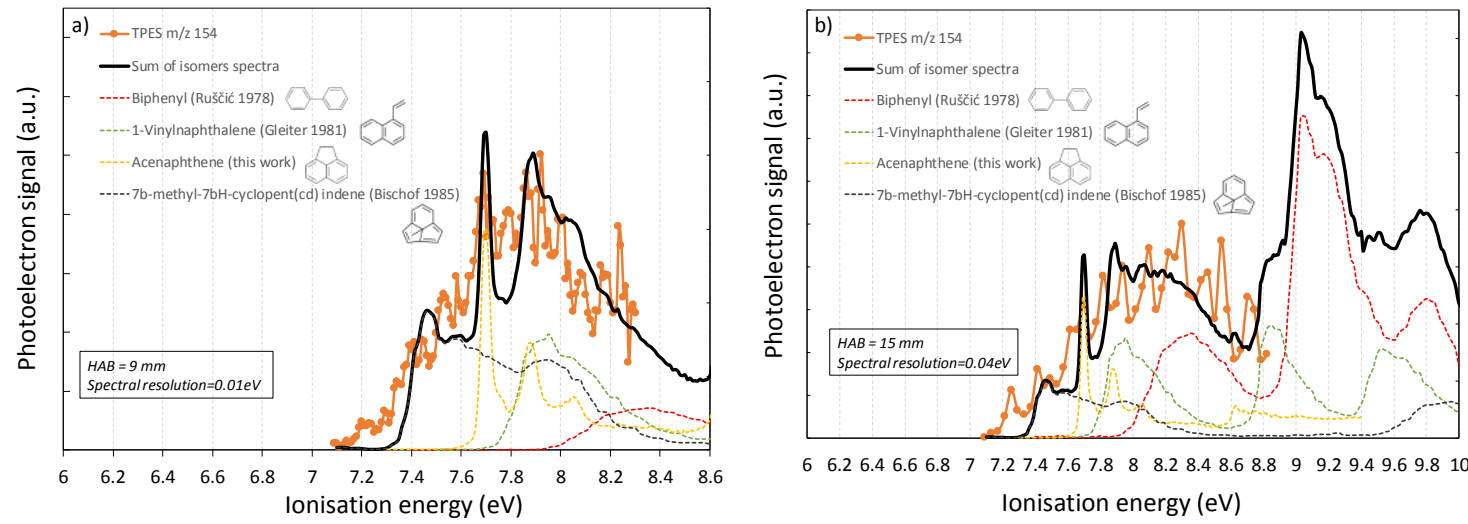

Figure 8: TPES of $154 \mathrm{~m} / \mathrm{z}$ at $\mathrm{HAB}=9$ and $15 \mathrm{~mm}$.

Comparison with a simulated spectrum (in black) corresponding to the sum of reference PES of biphenyl, 1vinylnaphthalene, acenaphthene and $7 b$-methyl-7bH-cyclopent(cd)indene for a signal ratio of 26:23:31:20 at

Considering all the available spectra in databases ${ }^{37,96}$, we can only select two species, 1vinylnaphthalene $\left(I E_{\mathrm{vert}}=7.89 \mathrm{eV}\right)$ and $7 \mathrm{~b}$-methyl-7bH-cyclopent $(\mathrm{cd})$ indene $\left(I E_{\mathrm{vert}}=7.56 \mathrm{eV}\right)$, potentially matching some of the spectral features experimentally observed in our TPES. Among these two species, 1-vinylnaphthalene is clearly expected to form in sooting flames according to the HACA mechanism ${ }^{7}$. 7b-methyl-7bH-cyclopent(cd)indene, to the best of our knowledge, has never been included in PAH growth models in rich flames. However, it was the only species proposed in literature possessing a spectral structure peaking around $7.5 \mathrm{eV}$ and thus matching the first rising shape of the experimental spectrum. 1-vinylnaphthalene, despite being more pertinent for soot formation and having an $I E$ value estimated around $7.55 \mathrm{eV}^{96}$, could not be

574 considered in the interpretation of the experimental data since no PES is currently available in 575 the literature.

Black spectra reported in fig. $8 \boldsymbol{a}$ and $8 \boldsymbol{b}$ correspond to the sum of the different contributions of the individual spectra of the four considered species. The best matching signal ratio that 578 reproduces the experimental spectra at respective $\mathrm{HAB}=9$ and $15 \mathrm{~mm}$ are biphenyl (26\% and $57957 \%)$, 1-vinylnaphthalene (23\% and 18\%), acenaphthene (31\% and $18 \%)$, 7b-methyl-7bH- 
cyclopent(cd)indene (20\% and $7 \%$ ). However, caution must be exerted regarding the level of

581 confidence in the identification. The most confident information from the comparison reported in 582 fig. $8 \boldsymbol{a}$ is the formation of acenaphthene characterized by a very specific peak in the experimental spectrum matching the adiabatic transition of this compound around $7.70 \mathrm{eV}$ and 584 probably also the second peak around $7.85 \mathrm{eV}$. Conversely, this spectrum does not conclude on 585 the formation of biphenyl at $\mathrm{HAB}=9 \mathrm{~mm}$. The main spectral features for this species are indeed 586 located above $9 \mathrm{eV}$, that is slightly off the spectral range of the current experimental spectrum. 587 However, the presence of biphenyl is more likely established on the less resolved TPES 588 spectrum recorded at $\mathrm{HAB}=15 \mathrm{~mm}$. As can be seen, biphenyl is the only species with spectral 589 features matching the shape of the spectrum between 8.2 and $8.8 \mathrm{eV}$. This part of the spectrum 590 strongly evolves between 9 to $15 \mathrm{~mm}$ and might therefore correspond to the increase of the 591 concentration of biphenyl with HAB. However, it is clear from the simulation that a spectrum 592 registered on a larger spectral energy scale (up to $10 \mathrm{eV}$ ) would provide more conclusive 593 information and confidence on the biphenyl formation, as well as having reference PES measured at higher resolution.

We can also note that the spectral features of 1-vinylnaphthalene match the experimental 596 spectrum in fig. $8 \boldsymbol{a}$ between 7.8 and $8.2 \mathrm{eV}$. However, this spectral region is relatively large and 597 does not display sufficient specific spectral features to allow a clear distinction of the species.

Finally, we have less confidence concerning the formation of $7 \mathrm{~b}-$ methyl-7bHcyclopent(cd)indene introduced in our simulated spectrum which appears atypical regarding 600 published chemical analysis of sooting flames. It would have been more interesting to have the 601 PES of 1-vinylnaphthalene which might also match the first spectral features of our TPES and is 602 more expected to be formed in sooting flames.

603 Hence, the analysis for the detected mass $154 \mathrm{~m} / z$, although incomplete, nevertheless 604 highlights the formation of several structural isomers in the nucleation region of the flame. It 
clearly indicates the formation of acenaphthene and very probably of biphenyl and 1-

606 vinylnaphthalene as well.

607

608

609

610

611

\subsubsection{Analysis of the species at $202 \mathrm{~m} / z\left(\mathrm{C}_{16} \mathrm{H}_{10}\right)$}

$202 \mathrm{~m} / \mathrm{z}$ is usually attributed to pyrene in the analysis of sooting flames carried out by mass spectrometry. Pyrene is considered as a crucial species in soot formation process, and often proposed as a key molecule in the nucleation step leading to the inception of NSPs ${ }^{7,52,54,97-99}$. In previous works on the same flame $e^{25,53}$, we not only showed the formation of pyrene in the nucleation region of this flame, but also of fluoranthene. Both compounds have been identified by JCLIF ${ }^{25}$. The mole fractions of pyrene and fluoranthene in this flame have been determined by JCLIF as $0.36 \mathrm{ppm}$ and $0.09 \mathrm{ppm}$ at $\mathrm{HAB}=9 \mathrm{~mm}$, respectively, and $0.34 \mathrm{ppm}$ and $0.12 \mathrm{ppm}$ at $\mathrm{HAB}=15 \mathrm{~mm}$, respectively ${ }^{25}$.

Hence, the study of the $202 \mathrm{~m} / \mathrm{z}$ with the TPES setup is a meaningful benchmark to evaluate its sensitivity in this lightly sooting flame environment. We report in fig.9 the TPES spectra measured at $\mathrm{HAB}=9$ and $15 \mathrm{~mm}$ with different spectral scan steps. We also report on these figures the calculated spectra (black line) corresponding to the sum of the adjusted contributions of the reference PES of pyrene (green dotted line) measured by Boschi et Schmidt $^{100}$ and fluoranthene (red dotted line) measured in this work (see fig.2). Moreover, we also considered the 9-ethynylphenanthrene (orange dotted line), also likely to form in this zone. We used for this species the referenced spectrum previously determined by Rouillé et al. ${ }^{74}$.

The relative contributions of pyrene and fluoranthene were adjusted for each HAB according to our previous mole fraction measurements in this flame by JCLIF. Based on these data, we obtained $x_{\text {pyrene }} / x_{\text {fluoranthene }}=4$ at $\mathrm{HAB}=9 \mathrm{~mm}$ and $x_{\text {pyrene }} / x_{\text {fluoranthene }}=3$ at $\mathrm{HAB}=15 \mathrm{~mm}$. Finally, we adjusted the contribution of 9-ethynylphenanthrene to get the best agreement between the global simulated spectrum with the experimental one for each HAB. It should be noted that we slightly degraded the resolution of the pyrene and fluoranthene spectra to match the experimental 
630 conditions of the spectrum recorded at $\mathrm{HAB}=15 \mathrm{~mm}$. Note also that this procedure assumes

631 equal absolute ionization cross-sections for all structural isomers. This assumption is confirmed

632 here by the good agreement obtained when using the mole fractions extracted from JCLIF to 633 match the experimental TPES.

634 The comparison reported in fig. 9a provides an excellent agreement between the experimental 635 spectrum and the simulated one obtained by adjusting the intensities of the pyrene and 636 fluoranthene contributions with the value of the corresponding mole fractions determined 637 previously ${ }^{25}$. This point hence validates the quantitative aspect of the TPES setup, providing 638 experimental spectra with intensities proportional to the concentrations of the measured species.

639 The spectrum in fig.9a shows an excellent match of the two first sharp features of the 640 experimental spectrum around $7.43 \mathrm{eV}$ and $7.58 \mathrm{eV}$ with the two first vibrational bands of 641 pyrene PES. These values are in excellent agreement with the $I E$ values $(7.43 \mathrm{eV}$ and $7.61 \mathrm{eV})$ of 642 the pyrene reference spectrum ${ }^{100}$. This experiment therefore demonstrates that pyrene can be 643 unambiguously identified by its PES measured with the TPES setup at this very low 644 concentration.

645
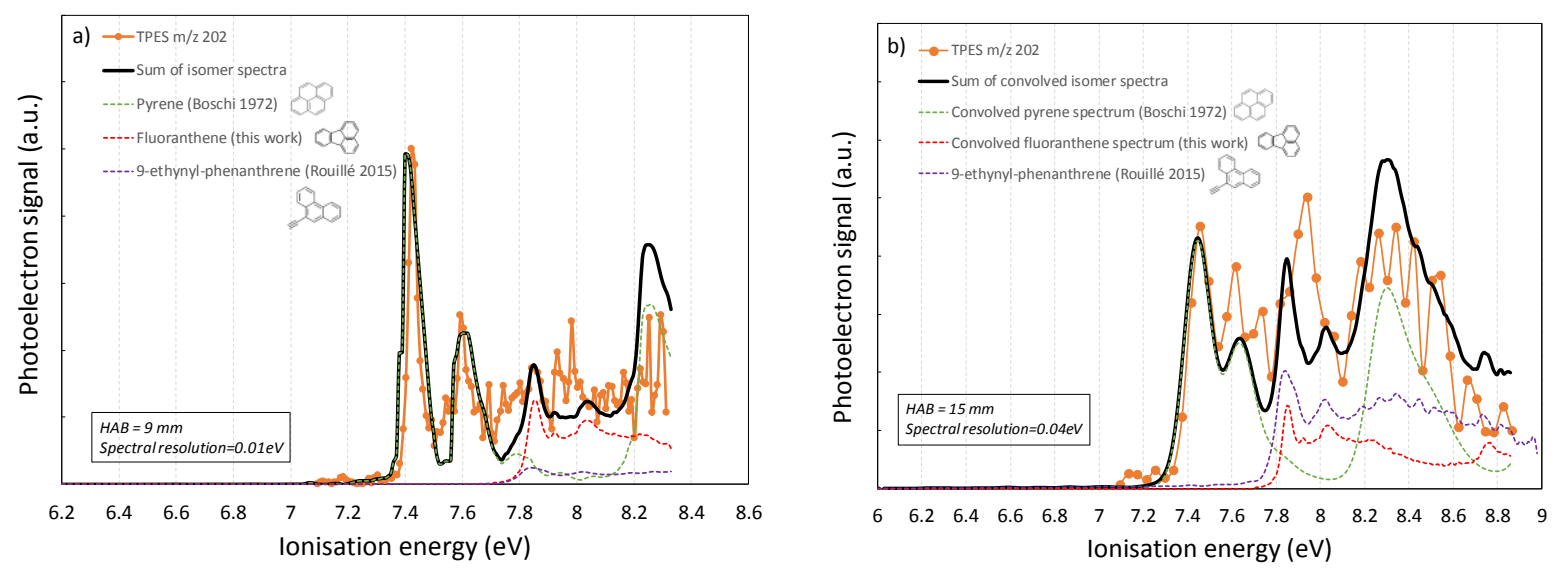

Figure 9: TPES spectra of $202 \mathrm{~m} / \mathrm{z}$ at $\mathrm{HAB}=9$ and $15 \mathrm{~mm}$.

648 Comparison with a simulated spectrum (in black) corresponding to the sum of reference PES of pyrene,

649 fluoranthene and 9-ethynyl-phenanthrene for a signal ratio of 77:19:4 at $9 \mathrm{~mm}$ and 56:18:26 at 15 mm. 
651 The section of the spectrum above $7.6 \mathrm{eV}$ is noisier but still exhibits a structure that can be 652 reproduced by the weighted sum of the pyrene and fluoranthene referenced PES. We can 653 however note a slight shift between the value of the experimental $(7.94 \mathrm{eV})$ and simulated (7.86 $654 \mathrm{eV})$ peak, corresponding to the $I E$ of the first band of fluoranthene. This difference is attributed 655 to the poor SNR in this zone of the spectrum due to the very weak mole fraction of fluoranthene 656 ( $\left.x_{\text {fluoranthene }}<0.1 \mathrm{ppm}\right)$, and to the overlap of the spectral contributions of pyrene and 657 fluoranthene. However, the experimental and simulated structures show a satisfying global 658 match allowing the identification of both pyrene and fluoranthene. This comparison also shows a 659 minor contribution of 9-ethynylphenanthrene to the overall spectral structure at HAB $=9 \mathrm{~mm}$. 660 The relative contributions we obtained this way were $77 \%, 19 \%$ and $4 \%$ respectively defining 661 the pyrene, fluoranthene and 9-ethynylphenanthrene contributions, although detection of the 662 latter is more speculative since its concentration would then be $0.01 \mathrm{ppm}$, well below our 663 estimated detection limit.

664 The spectrum recorded at $15 \mathrm{~mm}$ exhibits a different structure because of the more important 665 relative contribution of fluoranthene and 9-ethynylphenanthrene in comparison with pyrene in 666 this region of the flame. Again, the contributions of pyrene and fluoranthene have been adjusted 667 on previous JCLIF measurements at this HAB $\left(x_{\text {pyrene }} / x_{\text {fluoranthene }}=3\right)$, while the relative 668 contribution of 9-ethynylphenanthrene has been adjusted to obtain the best fit of the 669 experimental spectrum. The procedure leads to relative ratios of $56 \%, 18 \%$ and $26 \%$ for the 670 pyrene, fluoranthene and 9-ethynylphenanthrene contributions, respectively. As seen in Fig. 9b, 671 the experimental spectrum measured at $15 \mathrm{~mm}$ can still be correctly reproduced by the 672 contributions of these three species and shows a strong increase of the contribution of the 9673 ethynylphenanthrene. However, it would have been difficult to make this statement without the 674 knowledge of the relative contributions of pyrene and fluoranthene deduced from previous 
675 JCLIF measurements since fluoranthene and 9-ethynylphenanthrene have very similar spectra in 676 this spectral range. Therefore, to gain confidence in the attribution, acquisition up to $10 \mathrm{eV}$ 677 seems mandatory, as it would allow considering spectral features in a zone with less overlap 678 between the two species.

679 It should be noted that $202 \mathrm{~m} / \mathrm{z}$ has already been measured in rich or lightly sooting flames 680 studies and generally attributed to pyrene alone $e^{31,82}$ by the analysis of the PIE curves. However, 681 in two recent papers, Johansson et al. ${ }^{35,101}$ reported experimental PIE curves of $202 \mathrm{~m} / \mathrm{z}$ obtained 682 from condensed species onto incipient soot particles and sampled from different ethylene flames. 683 In these works, they concluded that their PIE curves could not be attributed to pyrene alone, and 684 that the contribution of fluoranthene had also to be considered. Here, we reach the same 685 conclusion for the gas phase. Interestingly, the adjusted contribution of these two PAHs (66\% 686 and 33\%) determined by Johansson et al. ${ }^{35}$ for the condensed species of $202 \mathrm{~m} / \mathrm{z}$ onto incipient soot particles is very similar to this work. This similarity is remarkable, considering the differences between these two flame setups (atmospheric pressure ethylene flame vs. low 689 pressure methane flame).

690 Hence, TPES data confirm the formation of fluoranthene (and probably 9691 ethynylphenanthrene) in addition to pyrene at $202 \mathrm{~m} / \mathrm{z}$, and highlights their potential implication 692 in the soot nucleation process, further reinforced by their presence as condensates onto incipient 693 soot particles ${ }^{35,101}$.

694

\subsubsection{Analysis of the species at $226 \mathrm{~m} / z\left(\mathrm{C}_{18} \mathrm{H}_{10}\right)$}

$226 \mathrm{~m} / \mathrm{z}$ is often attributed to CP-PAHs likely involved in the soot nucleation process ${ }^{11,12,101}$.

697 However, only a few analyses are reported in the literature and no clear attribution has ever been 698 reported before. Several factors can explain the difficulty to analyze $226 \mathrm{~m} / \mathrm{z}$ as the large number 699 of potential structural isomers and the lack of reference data such as IE, PIE curves or PES. To 
date, only five out of the whole possible structural isomers are listed in the online NIST

701 database $^{37}$, that furthermore only contains incomplete information: benzo[ghi]fluoranthene

and benz[mno]aceanthrylene ${ }^{200}$. It is worth noting that all these candidates are CP-PAHs containing a five-carbon ring in their structures. This lack of data makes therefore the 705 interpretation of $226 \mathrm{~m} / \mathrm{z}$ PES/TPES a very challenging task. In this work, we determined for the spectrum of which has been recorded by Rouillé et al. ${ }^{74}$

As for previous mass analyses, we report in fig.10 the TPES corresponding to $226 \mathrm{~m} / \mathrm{z}$ measured with different spectral resolutions and over different energy ranges at $\mathrm{HAB}=9$ and 15 and benzo(ghi)fluoranthene.
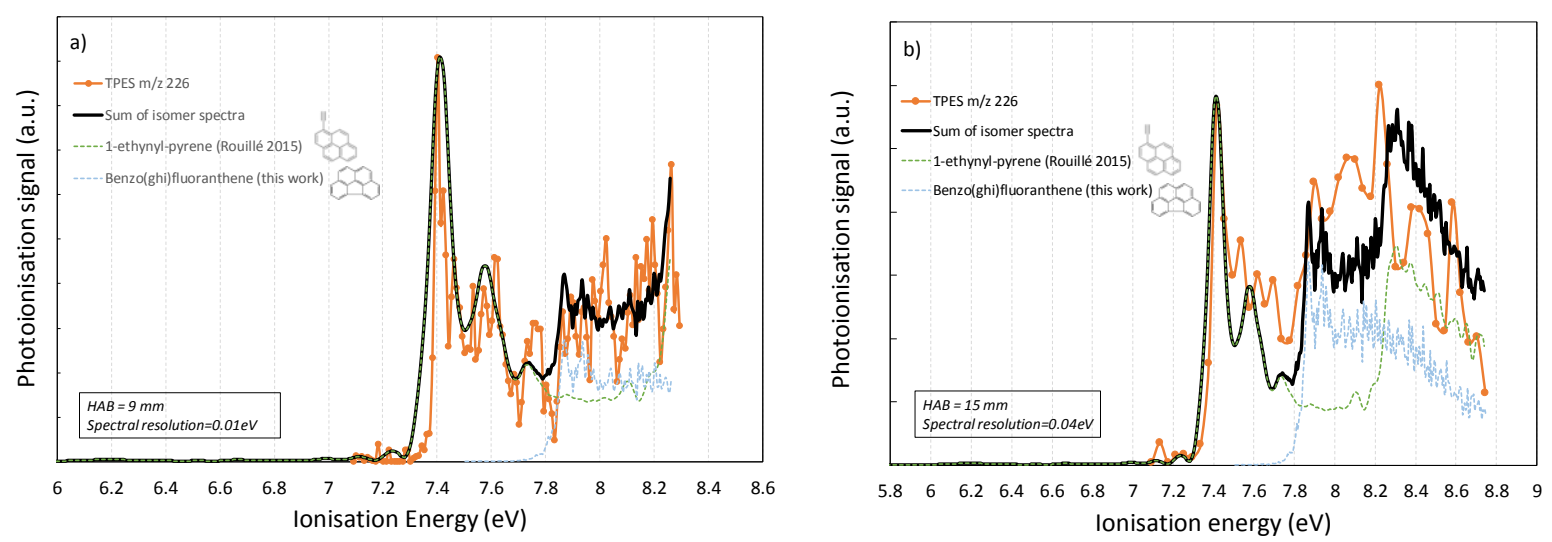

Figure 10: TPES of $226 \mathrm{~m} / \mathrm{z}$ at $\mathrm{HAB}=9$ and $15 \mathrm{~mm}$.

Comparison with a simulated spectrum (in black) corresponding to the sum of reference PES of 1-ethynyl-pyrene 
720 As seen in fig. 10a, the experimental and simulated spectra are in excellent agreement by considering only 1-ethynyl-pyrene and benzo(ghi)fluoranthene. An excellent match of the two first peaks of the experimental structure with the first two vibrational bands of 1-ethynyl-pyrene, peaking at 7.41 and $7.58 \mathrm{eV}$, is observed. The second part of the spectrum is noisier but also shows an excellent agreement with the adjusted contributions of both 1-ethynyl-pyrene and benzo(ghi)fluoranthene. We reached the best agreement by adjusting the relative signal contribution of 1-ethynyl-pyrene and benzo(ghi)fluoranthene equal to $77 \%$ and $23 \%$. The spectrum recorded at $\mathrm{HAB}=15 \mathrm{~mm}$ over a larger energy range still provides an adequate spectral resolution to identify these two species. The first peak of the spectrum is notably in perfect agreement with the energy of the first vibrational band of 1-ethynyl-pyrene. The rest of

730 the spectrum is globally correctly reproduced by the simulated structure by considering relative contributions of 1-ethynyl-pyrene and benzo(ghi)fluoranthene equal to $65 \%$ and $35 \%$. These data 732 show again that CP-PAH and substituted PAHs actively occur in the nucleation region of the 733 flame.

734 Recently, Adamson et al. $^{102}$ reported experiments, carried out with a tandem mass 735 spectrometer, showing the formation of aliphatically bridged structures in an ethylene $/ \mathrm{O}_{2}$ coflow 736 diffusion flame. These structures, constituted of PAHs bonded by a carbon chain, are suggested 737 as a particle seeds in sooting flames. Their formation would be based on a growth mechanism 738 involving side-substituted aromatics formed through reactions of smaller aromatic species and 739 aliphatic hydrocarbons. In this work, Adamson et al. ${ }^{102}$ notably detected the species $\mathrm{C}_{18} \mathrm{H}_{10}$ at $740226 \mathrm{~m} / \mathrm{z}$ as a very stable building block. The information provided in this work in the nucleation 741 zone, complementary highlights the formation of a side-substituted PAH as part of the 742 compounds detected at this mass and therefore their possible involvement in the formation of 743 such aliphatically-bridged PAHs. Furthermore, recent studies suggested that these compounds 
744 would be stable enough to resist in flame conditions ${ }^{103}$ and might be at the origin of the

745 broadband fluorescence emission spectra commonly observed in such sooting flames by laser

746 excitation $^{23,104}$ in the nucleation zone.

\section{Conclusion}

This work demonstrates and benchmarks the capabilities of the multiplex ${ }^{2}$ PEPICO 752 technique to study sooting flames. Mass-selected PES and TPES spectra corresponding to different PAHs have been reported for samples obtained at different heights above the burner in a sooting low-pressure methane flame. The identification of structural isomers at each $\mathrm{m} / \mathrm{z}$

755 channel relies on the comparison of the recorded experimental spectra with reference PES, which act as molecular fingerprints. From this work, it appears that the analysis of the TPES spectra enables the accurate identification of the PAHs formed in the flame. The PES, which are recorded at fixed photon energies with much shorter acquisition time than TPES scans, present a

759 less accurate resolution and lower SNR. However, these spectra have been shown for the 760 smallest species, at least up to naphthalene, to be sufficiently resolved to capture the main 761 electronic features of the PAHs and in some cases, even the vibrational progressions. However, 762 for the largest PAHs with concentrations below the ppm, we observed that only the TPES 763 approach provided sufficient sensitivity and spectral selectivity to enable the identification of the 764 different structural isomers.

765 This study provides evidence of the formation of CP-PAHs in the nucleation zone of the 766 sooting flame, such as indene, acenaphthylene, fluoranthene and benzo(ghi)fluoranthene. Such 767 CP-PAHs likely correspond to the cyclopentaring observed in the curved graphene layer present 768 in the core region of soot particles $^{55}$. Moreover, we also highlight the presence of side- 
substituted aromatics besides CP-PAHs which have been recently suggested to lead to the

770 formation of aliphatically bridged structures which could serve as a particle seed ${ }^{102}$. This work emphasizes the importance of considering the chemical pathways and overall kinetics leading to the formation of CP-PAHs and side-substituted aromatics in the development of soot formation mechanisms ${ }^{57}$.

This first attempt of using the PEPICO setup of the DESIRS beamline at SOLEIL for the study of low pressure sooting premixed flames therefore appears very encouraging and shows a high potential for understanding in situ the mechanisms of soot and PAHs formation in laboratory flames. Means of improvement include the recording of higher quality PES to feed the current database - to which this work has already contributed with the reporting of the PES of acenaphthene, acenaphthylene, fluoranthene and benzo(ghi)fluoranthene-or the challenging measurement or calculation of absolute cross-sections to increase the quantitative potential of this method. The sensitivity of the setup, although adequate, might be improved to provide a better identification of PAH isomers by increasing the molecular beam density in the ionization region (shortening the nozzle-synchrotron beam distance, improving the gas inlet). However, we showed that the capabilities of the current setup already enable the possibility of more systematic studies aiming at the determination of experimental profiles of moderate size PAHs isomers involved in the soot formation process in flames A deeper understanding of the soot nucleation process will require, at some point in the future, extending the measurements shown in this paper to the particulate phase at the very beginning of the soot formation. In this context, the use of the SAPHIRS chamber dedicated aerodynamic lens system, coupled to a thermodesorbing tip, could enable the measurements of the detailed chemical composition of nascent soot particles ${ }^{46}$. \\ 792 Acknowledgements}


This work is a contribution to the labex CAPPA and the CPER research project CLIMIBIO. The

authors thank the French Ministère de l'Enseignement Supérieur et de la Recherche, the Hauts de France Region and the European Funds for Regional Economical Development for their financial support to this project." We are grateful to J.-F. Gil for his technical help around the SAPHIRS set-up. We warmly thank the whole SOLEIL staff for running the facility and providing beamtime under project number 20151078 and 20170070.

\section{References}

1 J. C. Chow, Health Effects of Fine Particulate Air Pollution: Lines that Connect, Journal of the Air \& Waste Management Association, 2006, 56, 707-708.

2 T. Petry, P. Schmid and C. Schlatter, The use of toxic equivalency factors in assessing occupational and environmental health risk associated with exposure to airborne mixtures of polycyclic aromatic hydrocarbons (PAHs), Chemosphere, 1996, 32, 639-648.

3 R. Niranjan and A. K. Thakur, The Toxicological Mechanisms of Environmental Soot (Black Carbon) and Carbon Black: Focus on Oxidative Stress and Inflammatory Pathways, Front. Immunol., , DOI:10.3389/fimmu.2017.00763.

4 S. S. Lim, T. Vos, A. D. Flaxman, G. Danaei, K. Shibuya, H. Adair-Rohani, M. A. AlMazroa, M. Amann, H. R. Anderson, K. G. Andrews, M. Aryee, C. Atkinson, L. J. Bacchus, A. N. Bahalim, K. Balakrishnan, J. Balmes, S. Barker-Collo, A. Baxter, M. L. Bell, J. D. Blore, F. Blyth, C. Bonner, G. Borges, R. Bourne, M. Boussinesq, M. Brauer, P. Brooks, N. G. Bruce, B. Brunekreef, C. Bryan-Hancock, C. Bucello, R. Buchbinder, F. Bull, R. T. Burnett, T. E. Byers, B. Calabria, J. Carapetis, E. Carnahan, Z. Chafe, F. Charlson, H. Chen, J. S. Chen, A. T.-A. Cheng, J. C. Child, A. Cohen, K. E. Colson, B. C. Cowie, S. Darby, S. Darling, A. Davis, L. Degenhardt, F. Dentener, D. C. Des Jarlais, K. Devries, M. Dherani, E. L. Ding, E. R. Dorsey, T. Driscoll, K. Edmond, S. E. Ali, R. E. Engell, P. J. Erwin, S. Fahimi, G. Falder, F. Farzadfar, A. Ferrari, M. M. Finucane, S. Flaxman, F. G. R. Fowkes, G. Freedman, M. K. Freeman, E. Gakidou, S. Ghosh, E. Giovannucci, G. Gmel, K. Graham, R. Grainger, B. Grant, D. Gunnell, H. R. Gutierrez, W. Hall, H. W. Hoek, A. Hogan, H. D. Hosgood, D. Hoy, H. Hu, B. J. Hubbell, S. J. Hutchings, S. E. Ibeanusi, G. L. Jacklyn, R. Jasrasaria, J. B. Jonas, H. Kan, J. A. Kanis, N. Kassebaum, N. Kawakami, Y.-H. Khang, S. Khatibzadeh, J.-P. Khoo, C. Kok, F. Laden, R. Lalloo, Q. Lan, T. Lathlean, J. L. Leasher, J. Leigh, Y. Li, J. K. Lin, S. E. Lipshultz, S. London, R. Lozano, Y. Lu, J. Mak, R. Malekzadeh, L. Mallinger, W. Marcenes, L. March, R. Marks, R. Martin, P. McGale, J. McGrath, S. Mehta, Z. A. Memish, G. A. Mensah, T. R. Merriman, R. Micha, C. Michaud, V. Mishra, K. M. Hanafiah, A. A. Mokdad, L. Morawska, D. Mozaffarian, T. Murphy, M. Naghavi, B. Neal, P. K. Nelson, J. M. Nolla, R. Norman, C. Olives, S. B. Omer, J. Orchard, R. Osborne, B. Ostro, A. Page, K. D. Pandey, C. D. Parry, E. Passmore, J. Patra, N. Pearce, P. M. Pelizzari, M. Petzold, M. R. Phillips, D. Pope, C. A. Pope, J. Powles, M. Rao, H. Razavi, E. A. Rehfuess, J. T. Rehm, B. Ritz, F. P. 

Rosenfeld, A. Roy, L. Rushton, J. A. Salomon, U. Sampson, L. Sanchez-Riera, E. Sanman, A. Sapkota, S. Seedat, P. Shi, K. Shield, R. Shivakoti, G. M. Singh, D. A. Sleet, E. Smith, K. R. Smith, N. J. Stapelberg, K. Steenland, H. Stöckl, L. J. Stovner, K. Straif, L. Straney, G. D. Thurston, J. H. Tran, R. Van Dingenen, A. van Donkelaar, J. L. Veerman, L. Vijayakumar, R. Weintraub, M. M. Weissman, R. A. White, H. Whiteford, S. T. Wiersma, J. D. Wilkinson, H. C. Williams, W. Williams, N. Wilson, A. D. Woolf, P. Yip, J. M. Zielinski, A. D. Lopez, C. J. Murray and M. Ezzati, A comparative risk assessment of burden of disease and injury attributable to 67 risk factors and risk factor clusters in 21 regions, 1990-2010: a systematic analysis for the Global Burden of Disease Study 2010, The Lancet, 2012, 380, 2224-2260.

5 T. C. Bond, S. J. Doherty, D. W. Fahey, P. M. Forster, T. Berntsen, B. J. DeAngelo, M. G. Flanner, S. Ghan, B. Kärcher, D. Koch, S. Kinne, Y. Kondo, P. K. Quinn, M. C. Sarofim, M. G. Schultz, M. Schulz, C. Venkataraman, H. Zhang, S. Zhang, N. Bellouin, S. K. Guttikunda, P. K. Hopke, M. Z. Jacobson, J. W. Kaiser, Z. Klimont, U. Lohmann, J. P. Schwarz, D. Shindell, T. Storelvmo, S. G. Warren and C. S. Zender, Bounding the role of black carbon in the climate system: A scientific assessment, Journal of Geophysical Research: Atmospheres, 2013, 118, 5380-5552.

6 B. Gorbunov, A. Baklanov, N. Kakutkina, H. L. Windsor and R. Toumi, Ice nucleation on soot particles, Journal of Aerosol Science, 2001, 32, 199-215.

7 M. Frenklach and H. Wang, Detailed modeling of soot particle nucleation and growth, Symposium (International) on Combustion, 1991, 23, 1559-1566.

8 A. D'Anna, Combustion Generated Fine Carbonaceous Particles, KIT Scientific Publishing, Karlsruhe, 2009.

9 A. D'Anna, Combustion-formed nanoparticles, Proceedings of the Combustion Institute, 2009, 32, 593-613.

$10 \mathrm{H}$. Wang, Formation of nascent soot and other condensed-phase materials in flames, Proceedings of the Combustion Institute, 2011, 33, 41-67.

$11 \mathrm{~B}$. Shukla and M. Koshi, A novel route for PAH growth in HACA based mechanisms, Combustion and Flame, 2012, 159, 3589-3596.

12B. Shukla and M. Koshi, Comparative study on the growth mechanisms of PAHs, Combustion and Flame, 2011, 158, 369-375.

13C. S. McEnally, L. D. Pfefferle, B. Atakan and K. Kohse-Höinghaus, Studies of aromatic hydrocarbon formation mechanisms in flames: Progress towards closing the fuel gap, Progress in Energy and Combustion Science, 2006, 32, 247-294.

14M. Commodo, K. Kaiser, G. De Falco, P. Minutolo, F. Schulz, A. D’Anna and L. Gross, On the early stages of soot formation: Molecular structure elucidation by high-resolution atomic force microscopy, Combustion and Flame, 2019, 205, 154-164.

15 K. Siegmann and K. Sattler, Formation mechanism for polycyclic aromatic hydrocarbons in methane flames, J. Chem. Phys., 1999, 112, 698-709.

16J. Xiao, E. Austin and W. L. Roberts, Relative Polycyclic Aromatic Hydrocarbon Concentrations in Unsteady Counterflow Diffusion Flames, Combustion Science and Technology, 2005, 177, 691-713.

17 S. Bejaoui, X. Mercier, P. Desgroux and E. Therssen, Laser induced fluorescence spectroscopy of aromatic species produced in atmospheric sooting flames using UV and visible excitation wavelengths, Combustion and Flame, 2014, 161, 2479-2491.

18 K. C. Smyth, C. R. Shaddix and D. A. Everest, Aspects of soot dynamics as revealed by measurements of broadband fluorescence and flame luminosity in flickering diffusion flames, Combustion and Flame, 1997, 111, 185-207.

19S.-Y. Lee, S. R. Turns and R. J. Santoro, Measurements of soot, OH, and PAH concentrations in turbulent ethylene/air jet flames, Combustion and Flame, 2009, 156, 2264-2275. 
20M. Köhler, K. P. Geigle, T. Blacha, P. Gerlinger and W. Meier, Experimental characterization and numerical simulation of a sooting lifted turbulent jet diffusion flame, Combustion and Flame, 2012, 159, 2620-2635.

21 A. Ciajolo, R. Ragucci, B. Apicella, R. Barbella, M. de Joannon and A. Tregrossi, Fluorescence spectroscopy of aromatic species produced in rich premixed ethylene flames, Chemosphere, 2001, 42, 835-841.

22 M. Sirignano, A. Collina, M. Commodo, P. Minutolo and A. D'Anna, Detection of aromatic hydrocarbons and incipient particles in an opposed-flow flame of ethylene by spectral and time-resolved laser induced emission spectroscopy, Combustion and Flame, 2012, 159, 16631669.

23X. Mercier, O. Carrivain, C. Irimiea, A. Faccinetto and E. Therssen, Dimers of polycyclic aromatic hydrocarbons: the missing pieces in the soot formation process, Phys. Chem. Chem. Phys., 2019, 21, 8282-8294.

24 Y. Zhang, Y. Li, L. Wang, P. Liu, R. Zhan, Z. Huang and H. Lin, Investigation on the LIF spectrum superposition of gas-phase PAH mixtures at elevated temperatures: potential for the analysis of PAH LIF spectra in sooting flames, Appl. Phys. B, 2019, 125, 72.

25T. Mouton, X. Mercier and P. Desgroux, Isomer discrimination of PAHs formed in sooting flames by jet-cooled laser-induced fluorescence: application to the measurement of pyrene and fluoranthene, Applied Physics B, 2016, 122, 123-139.

26X. Mercier, M. Wartel, J.-F. Pauwels and P. Desgroux, Implementation of a new spectroscopic method to quantify aromatic species involved in the formation of soot particles in flames, Applied Physics B: Lasers and Optics, 2008, 91, 387-395.

27 C. A. Taatjes, N. Hansen, D. L. Osborn, K. Kohse-Hoinghaus, T. A. Cool and P. R. Westmoreland, "Imaging" combustion chemistry via multiplexed synchrotron-photoionization mass spectrometry, Physical Chemistry Chemical Physics, 2008, 10, 20-34.

28F. Qi, R. Yang, B. Yang, C. Huang, L. Wei, J. Wang, L. Sheng and Y. Zhang, Isomeric identification of polycyclic aromatic hydrocarbons formed in combustion with tunable vacuum ultraviolet photoionization, Review of Scientific Instruments, 2006, 77, 084101.

29L. Zhao, R. I. Kaiser, B. Xu, U. Ablikim, M. Ahmed, D. Joshi, G. Veber, F. R. Fischer and A. M. Mebel, Pyrene synthesis in circumstellar envelopes and its role in the formation of 2D nanostructures, 2018, 2, 413-419.

30F. Qi, Combustion Chemistry Probed by Synchrotron VUV Photo-ionization Mass Spectrometry, Proceedings of the Combustion Institute, 2013, 34, 33-63.

31 Y. Li, L. Zhang, Z. Tian, T. Yuan, J. Wang, B. Yang and F. Qi, Experimental Study of a FuelRich Premixed Toluene Flame at Low Pressure, Energy Fuels, 2009, 23, 1473-1485.

32 Y. Li, Z. Tian, L. Zhang, T. Yuan, K. Zhang, B. Yang and F. Qi, An experimental study of the rich premixed ethylbenzene flame at low pressure, Proceedings of the Combustion Institute, 2009, 32, 647-655.

33 Y. Li, L. Zhang, Z. Tian, T. Yuan, K. Zhang, B. Yang and F. Qi, Investigation of the rich premixed laminar acetylene/oxygen/argon flame: Comprehensive flame structure and special concerns of polyynes, Proceedings of the Combustion Institute, 2009, 32, 1293-1300.

34B. Yang, Y. Li, L. Wei, C. Huang, J. Wang, Z. Tian, R. Yang, L. Sheng, Y. Zhang and F. Qi, An experimental study of the premixed benzene/oxygen/argon flame with tunable synchrotron photoionization, Proceedings of the Combustion Institute, 2007, 31, 555-563.

35 K. O. Johansson, J. Zádor, P. Elvati, M. F. Campbell, P. E. Schrader, N. K. RichardsHenderson, K. R. Wilson, A. Violi and H. A. Michelsen, Critical Assessment of Photoionization Efficiency Measurements for Characterization of Soot-Precursor Species, $J$. Phys. Chem. A, 2017, 121, 4475-4485.

36T. Zhang, L. Zhang, X. Hong, K. Zhang, F. Qi, C. K. Law, T. Ye, P. Zhao and Y. Chen, An experimental and theoretical study of toluene pyrolysis with tunable synchrotron VUV 
photoionization and molecular-beam mass spectrometry, Combustion and Flame, 2009, 156, 2071-2083.

37 S. G. Lias, in NIST Chemistry WebBook, NIST Standard Reference Database Number 69, edited by P. J. Linstrom and W. G. Mallard (National Institute of Standards and Technology, Gaithersburg, MD), 20899. http://webbook.nist.gov/chemistry/. Accessed 26 November 2012, 2012.

38P. Bréchignac, G. A. Garcia, C. Falvo, C. Joblin, D. Kokkin, A. Bonnamy, P. Parneix, T. Pino, O. Pirali, G. Mulas and L. Nahon, Photoionization of cold gas phase coronene and its clusters: Autoionization resonances in monomer, dimer, and trimer and electronic structure of monomer cation, J. Chem. Phys., 2014, 141, 164325.

39P. Oßwald, P. Hemberger, T. Bierkandt, E. Akyildiz, M. Köhler, A. Bodi, T. Gerber and T. Kasper, In situ flame chemistry tracing by imaging photoelectron photoion coincidence spectroscopy, Review of Scientific Instruments, 2014, 85, 025101.

40D. Felsmann, K. Moshammer, J. Krüger, A. Lackner, A. Brockhinke, T. Kasper, T. Bierkandt, E. Akyildiz, N. Hansen, A. Lucassen, P. Oßwald, M. Köhler, G. A. Garcia, L. Nahon, P. Hemberger, A. Bodi, T. Gerber and K. Kohse-Höinghaus, Electron ionization, photoionization and photoelectron/photoion coincidence spectroscopy in mass-spectrometric investigations of a low-pressure ethylene/oxygen flame, Proceedings of the Combustion Institute, 2015, 35 , 779-786.

41 D. Felsmann, A. Lucassen, J. Krüger, C. Hemken, L.-S. Tran, J. Pieper, G. A. Garcia, A. Brockhinke, L. Nahon and K. Kohse-Höinghaus, Progress in Fixed-Photon-Energy TimeEfficient Double Imaging Photoelectron/Photoion Coincidence Measurements in Quantitative Flame Analysis, Zeitschrift für Physikalische Chemie, 2016, 230, 1067-1097.

42 J. Pieper, S. Schmitt, C. Hemken, E. Davies, J. Wullenkord, A. Brockhinke, J. Krüger, G. A. Garcia, L. Nahon, A. Lucassen, W. Eisfeld and K. Kohse-Höinghaus, Isomer Identification in Flames with Double-Imaging Photoelectron/Photoion Coincidence Spectroscopy (i2PEPICO) using Measured and Calculated Reference Photoelectron Spectra, Zeitschrift für Physikalische Chemie, 2018, 232, 153-187.

43 J. Krüger, G. A. Garcia, D. Felsmann, K. Moshammer, A. Lackner, A. Brockhinke, L. Nahon and K. Kohse-Höinghaus, Photoelectron-photoion coincidence spectroscopy for multiplexed detection of intermediate species in a flame, Phys. Chem. Chem. Phys., 2014, 16, 2279122804.

44P. Hemberger, V. B. F. Custodis, A. Bodi, T. Gerber and J. A. van Bokhoven, Understanding the mechanism of catalytic fast pyrolysis by unveiling reactive intermediates in heterogeneous catalysis, Nat Commun, 2017, 8, 1-9.

45D. Krüger, P. Oßwald, M. Köhler, P. Hemberger, T. Bierkandt, Y. Karakaya and T. Kasper, Hydrogen abstraction ratios: A systematic iPEPICO spectroscopic investigation in laminar flames, Combustion and Flame, 2018, 191, 343-352.

46 M. T. Baeza-Romero, F. Gaie-Levrel, A. Mahjoub, V. López-Arza, G. A. Garcia and L. Nahon, A smog chamber study coupling a photoionization aerosol electron/ion spectrometer to VUV synchrotron radiation: organic and inorganic-organic mixed aerosol analysis, Eur. Phys. J. D, 2016, 70, 154.

47 J. Bourgalais, Z. Gouid, O. Herbinet, G. A. Garcia, P. Arnoux, Z. Wang, L.-S. Tran, G. Vanhove, M. Hochlaf, L. Nahon and F. Battin-Leclerc, Isomer-sensitive characterization of low temperature oxidation reaction products by coupling a jet-stirred reactor to an electron/ion coincidence spectrometer: case of n-pentane, Phys. Chem. Chem. Phys., 2020, 22, 1222-1241. 48 A. Bodi, P. Hemberger, D. L. Osborn and B. Sztáray, Mass-Resolved Isomer-Selective Chemical Analysis with Imaging Photoelectron Photoion Coincidence Spectroscopy, J. Phys. Chem. Lett., 2013, 4, 2948-2952. 
982

983

984

985

986

987

988

989

990

991

992

993

994

995

996

997

998

999

1000

1001

1002

1003

1004

1005

1006

1007

1008

1009

1010

1011

1012

1013

1014

1015

1016

1017

1018

1019

1020

1021

1022

1023

1024

1025

1026

1027

1028

1029

1030

1031

49 M. Wartel, J.-F. Pauwels, P. Desgroux and X. Mercier, Pyrene Measurements in Sooting Low Pressure Methane Flames by Jet-Cooled Laser-Induced Fluorescence, Journal of Physical Chemistry A, 2011, 115, 14153-14162.

50H. Bladh, N.-E. Olofsson, T. Mouton, J. Simonsson, X. Mercier, A. Faccinetto, P.-E. Bengtsson and P. Desgroux, Probing the smallest soot particles in low-sooting premixed flames using laser-induced incandescence, Proceedings of the Combustion Institute, 2015, 35, $1843-1850$.

51 T. Mouton, X. Mercier, M. Wartel, N. Lamoureux and P. Desgroux, Laser-induced incandescence technique to identify soot nucleation and very small particles in low-pressure methane flames, Applied Physics B: Lasers and Optics, 2013, 112, 369-379.

52 A. El Bakali, X. Mercier, M. Wartel, F. Acevedo, I. S. Burns, L. Gasnot, J.-F. Pauwels and P. Desgroux, Modeling of PAHs in low pressure sooting premixed methane flame, Energy, 2012, 43, 73-84.

53P. Desgroux, A. Faccinetto, X. Mercier, T. Mouton, D. Aubagnac Karkar and A. El Bakali, Comparative study of the soot formation process in a "nucleation" and a "sooting" low pressure premixed methane flame, Combustion and Flame, 2017, 184, 153-166.

54D. Aubagnac-Karkar, A. El Bakali and P. Desgroux, Soot particles inception and PAH condensation modelling applied in a soot model utilizing a sectional method, Combustion and Flame, 2018, 189, 190-206.

55 J.-O. Müller, D. S. Su, U. Wild and R. Schlögl, Bulk and surface structural investigations of diesel engine soot and carbon black, Phys. Chem. Chem. Phys., 2007, 9, 4018-4025.

56 M. Wei, T. Zhang, X. Chen, F. Yan, G. Guo and D. Zhang, Formation of bicyclic polycyclic aromatic hydrocarbons (PAHs) from the reaction of a phenyl radical with cis-3-penten-1-yne, RSC Adv., 2018, 8, 13226-13236.

57 M. Frenklach and A. M. Mebel, On the mechanism of soot nucleation, Phys. Chem. Chem. Phys., 2020, 22, 5314-5331.

58R. A. Krueger and G. Blanquart, Predicting the photoresponse of soot nuclei: Spectroscopic characteristics of aromatic aggregates containing five-membered rings, Combustion and Flame, 2020, 217, 85-92.

59M. Tia, B. Cunha de Miranda, S. Daly, F. Gaie-Levrel, G. A. Garcia, I. Powis and L. Nahon, Chiral Asymmetry in the Photoionization of Gas-Phase Amino-Acid Alanine at Lyman- $\alpha$ Radiation Wavelength, J. Phys. Chem. Lett., 2013, 4, 2698-2704.

60X. Tang, G. A. Garcia, J.-F. Gil and L. Nahon, Vacuum upgrade and enhanced performances of the double imaging electron/ion coincidence end-station at the vacuum ultraviolet beamline DESIRS, Review of Scientific Instruments, 2015, 86, 123108.

61 L. Nahon, N. de Oliveira, G. A. Garcia, J.-F. Gil, B. Pilette, O. Marcouillé, B. Lagarde and F. Polack, DESIRS: a state-of-the-art VUV beamline featuring high resolution and variable polarization for spectroscopy and dichroism at SOLEIL, J Synchrotron Rad, 2012, 19, 508520 .

62 B. Mercier, M. Compin, C. Prevost, G. Bellec, R. Thissen, O. Dutuit and L. Nahon, Experimental and theoretical study of a differentially pumped absorption gas cell used as a low energy-pass filter in the vacuum ultraviolet photon energy range, Journal of Vacuum Science \& Technology A, 2000, 18, 2533-2541.

$63 \mathrm{~K}$. Yoshino and Y. Tanaka, Absorption spectrum of krypton in the vacuum uv region, J. Opt. Soc. Am., JOSA, 1979, 69, 159-165.

64G. A. Garcia, B. K. Cunha de Miranda, M. Tia, S. Daly and L. Nahon, DELICIOUS III: a multipurpose double imaging particle coincidence spectrometer for gas phase vacuum ultraviolet photodynamics studies, Rev Sci Instrum, 2013, 84, 053112.

65 G. A. Garcia, X. Tang, J.-F. Gil, L. Nahon, M. Ward, S. Batut, C. Fittschen, C. A. Taatjes, D. L. Osborn and J.-C. Loison, Synchrotron-based double imaging photoelectron/photoion 
coincidence spectroscopy of radicals produced in a flow tube: $\mathrm{OH}$ and OD, J. Chem. Phys., 2015, 142, 164201.

66 J. C. Poully, J. P. Schermann, N. Nieuwjaer, F. Lecomte, G. Grégoire, C. Desfrançois, G.

1035

1036

1037

1038

1039

1040

1041

1042

1043

1044

1045

1046

1047

1048

1049

1050

1051

1052

1053

1054

1055

1056

1057

1058

1059

1060

1061

1062

1063

1064

1065

1066

1067

1068

1069

1070

1071

1072

1073

1074

1075

1076

1077

1078

1079

A. Garcia, L. Nahon, D. Nandi, L. Poisson and M. Hochlaf, Photoionization of 2-pyridone and 2-hydroxypyridine, Physical Chemistry Chemical Physics, 2010, 12, 3566-3572.

67 M. Wartel, J.-F. Pauwels, P. Desgroux and X. Mercier, Quantitative measurement of naphthalene in low-pressure flames by jet-cooled laser-induced fluorescence, Applied Physics B: Lasers and Optics, 2010, 100, 933-943.

68 T. S. Kasper, P. Oßwald, M. Kamphus and K. Kohse-Höinghaus, Ethanol flame structure investigated by molecular beam mass spectrometry, Combustion and Flame, 2007, 150, 220 231.

69 N. Hansen, T. Kasper, S. J. Klippenstein, P. R. Westmoreland, M. E. Law, C. A. Taatjes, K. Kohse-Höinghaus, J. Wang and T. A. Cool, Initial Steps of Aromatic Ring Formation in a Laminar Premixed Fuel-Rich Cyclopentene Flame, Journal of Physical Chemistry A, 2007, 111, 4081-4092.

70H.-S. Kim, D. R. Wagner and R. J. Saykally, Single Photon Infrared Emission Spectroscopy of the Gas Phase Pyrene Cation: Support for a Polycyclic Aromatic Hydrocarbon Origin of the Unidentified Infrared Emission Bands, Phys. Rev. Lett., 2001, 86, 5691-5694.

71 J. E. Elsila, N. P. de Leon and R. N. Zare, Factors Affecting Quantitative Analysis in Laser Desorption/Laser Ionization Mass Spectrometry, Analytical Chemistry, 2004, 76, 2430-2437.

72 M. K. Spencer, M. R. Hammond and R. N. Zare, Laser mass spectrometric detection of extraterrestrial aromatic molecules: Mini-review and examination of pulsed heating effects, PNAS, 2008, 105, 18096-18101.

73P. M. Mayer, V. Blanchet and C. Joblin, Threshold photoelectron study of naphthalene, anthracene, pyrene, 1,2-dihydronaphthalene, and 9,10-dihydroanthracene, J. Chem. Phys., 2011, 134, 244312.

74G. Rouillé, S. Krasnokutski, D. Fulvio, C. Jäger, T. Henning, G. Garcia, X. Tang and L. Nahon, Dissociative photoionization of polycyclic aromatic hydrocarbon molecules carrying an ethynyl group, The Astrophysical Journal, , DOI:10.1088/0004-637X/810/2/114.

75 R. Boschi, E. Clar and W. Schmidt, Photoelectron spectra of polynuclear aromatics. III. The effect of nonplanarity in sterically overcrowded aromatic hydrocarbons, J. Chem. Phys., 1974, 60, 4406-4418.

76M. J. S. Dewar, E. Haselbach and S. D. Worley, Calculated and observed ionization potentials of unsaturated polycyclic hydrocarbons; calculated heats of formation by several semiempirical s. c. f. m.o. methods, Proceedings of the Royal Society of London. A. Mathematical and Physical Sciences, 1970, 315, 431-442.

$77 \mathrm{M}$. Meot-Ner, Ion thermochemistry of low-volatility compounds in the gas phase. 3. Polycyclic aromatics: ionization energies, proton and hydrogen affinities. Extrapolations to graphite, J. Phys. Chem., 1980, 84, 2716-2723.

78 M. Kinoshita, The Absorption Spectra of the Molecular Complexes of Aromatic Compounds with p-Bromanil, BCSJ, 1962, 35, 1609-1611.

79E. Heilbronner, T. Hoshi, J. L. von Rosenberg and K. Hafner, Alkyl-induced, natural hypsochromic shifts of the $2 \mathrm{~A} \leftarrow 2 \mathrm{X}$ and $2 \mathrm{~B} \leftarrow 2 \mathrm{X}$ transitions of azulene and naphthalene radical cations, Nouv. J. Chim., 1976, 1, 105.

80 Y. Ling and C. Lifshitz, Time-Dependent Mass Spectra and Breakdown Graphs. 19. Fluoranthene, J. Phys. Chem., 1995, 99, 11074-11080.

81 M. A. Slifkin and A. C. Allison, Measurement of Ionization Potentials from Contact Charge Transfer Spectra, Nature, 1967, 215, 949-950. 
1080

1081

1082

1083

1084

1085

1086

1087

1088

1089

1090

1091

1092

1093

1094

1095

1096

1097

1098

1099

1100

1101

1102

1103

1104

1105

1106

1107

1108

1109

1110

1111

1112

1113

1114

1115

1116

1117

1118

1119

1120

1121

1122

1123

1124

1125

1126

1127

1128

1129

82 Y. Li, L. Zhang, T. Yuan, K. Zhang, J. Yang, B. Yang, F. Qi and C. K. Law, Investigation on fuel-rich premixed flames of monocyclic aromatic hydrocarbons: Part I. Intermediate identification and mass spectrometric analysis, Combustion and Flame, 2010, 157, 143-154.

83 L. Klasinc, B. Kovac and H. Gusten, Photoelectron spectra of acenes. Electronic structure and substituent effects, Pure and Applied Chemistry, 1983, 55, 289-298.

84E. Heilbronner, R. Gleiter, H. Hopf, V. Hornung and A. De Meijere, PhotoelectronSpectroscopic Evidence for the Orbital Sequence in Fulvene and 3, 4-Dimethylenecyclobutene, Helvetica Chimica Acta, 1971, 54, 783-794.

85 P. A. Clark, F. Brogli and E. Heilbronner, The $\pi$-Orbital Energies of the Acenes, Helvetica Chimica Acta, 1972, 55, 1415-1428.

86T. A. Cool, J. Wang, K. Nakajima, C. A. Taatjes and A. Mcllroy, Photoionization cross sections for reaction intermediates in hydrocarbon combustion, International Journal of Mass Spectrometry, 2005, 247, 18-27.

87E. E. Rennie, C. a. F. Johnson, J. E. Parker, D. M. P. Holland, D. A. Shaw and M. A. Hayes, A photoabsorption, photodissociation and photoelectron spectroscopy study of $\mathrm{C} 6 \mathrm{H} 6$ and C6D6, Chemical Physics, 1998, 229, 107-123.

88 S. Soorkia, A. J. Trevitt, T. M. Selby, D. L. Osborn, C. A. Taatjes, K. R. Wilson and S. R. Leone, Reaction of the C2H Radical with 1-Butyne (C4H6): Low-Temperature Kinetics and Isomer-Specific Product Detection, J. Phys. Chem. A, 2010, 114, 3340-3354.

89P. Carlier and G. Mouvier, Etude par spectrometrie de photoelectrons de la structure electronique des phenyl-alcynes conjugues, Journal of Electron Spectroscopy and Related Phenomena, 1979, 16, 169-181.

90B. West, A. Sit, A. Bodi, P. Hemberger and P. M. Mayer, Dissociative Photoionization and Threshold Photoelectron Spectra of Polycyclic Aromatic Hydrocarbon Fragments: An Imaging Photoelectron Photoion Coincidence (iPEPICO) Study of Four Substituted Benzene Radical Cations, The Journal of Physical Chemistry A, 2014, 118, 11226-11234.

91F. Zhang, R. I. Kaiser, V. V. Kislov, A. M. Mebel, A. Golan and M. Ahmed, A VUV Photoionization Study of the Formation of the Indene Molecule and Its Isomers, J. Phys. Chem. Lett., 2011, 2, 1731-1735.

92C. R. Brundle, M. B. Robin and N. A. Kuebler, Perfluoro effect in photoelectron spectroscopy. II. Aromatic molecules, J. Am. Chem. Soc., 1972, 94, 1466-1475.

93D. Dougherty, J. Lewis, R. V. Nauman and S. P. McGlynn, Photoelectron spectroscopy of azulenes, Journal of Electron Spectroscopy and Related Phenomena, 1980, 19, 21-33.

94C.-H. Chin, T. Zhu and J. Z. Zhang, Theoretical Investigations of Photoionization Efficiency of Naphthalene, , DOI:10.26434/chemrxiv.7665620.v1.

95R. Gleiter, W. Schäfer and M. Eckert- Maksić, Transannulare Wechselwirkungen zwischen Acetylenen - Photoelektronenspektroskopische Untersuchungen an 1,8-Diethinylnaphthalin und cyclischen Derivaten von 2,2'-Diethinylbiphenyl, Chemische Berichte, 1981, 114, 2309 2321.

96 Y. Y. Li, Y. JiuZhong and C. ZhanJun, Photonionization Cross Section Database (Version 2.0)., http://flame.nsrl.ustc.edu.cn/database/.

97 J. Appel, H. Bockhorn and M. Wulkow, A detailed numerical study of the evolution of soot particle size distributions in laminar premixed flames, Chemosphere, 2001, 42, 635-645.

98 N. A. Eaves, S. B. Dworkin and M. J. Thomson, Assessing relative contributions of PAHs to soot mass by reversible heterogeneous nucleation and condensation, Proceedings of the Combustion Institute, 2017, 36, 935-945.

99C. A. Schuetz and M. Frenklach, Nucleation of soot: Molecular dynamics simulations of pyrene dimerization, Proceedings of the Combustion Institute, 2002, 29, 2307-2314.

100 R. Boschi and W. Schmidt, Photoelectron spectra of polycyclic aromatic hydrocarbons. Pyrene and coronene, Tetrahedron Letters, 1972, 13, 2577-2580. 
$1130101 \quad$ K. O. Johansson, T. Dillstrom, P. Elvati, M. F. Campbell, P. E. Schrader, D. M. PopolanVaida, N. K. Richards-Henderson, K. R. Wilson, A. Violi and H. A. Michelsen, Radicalradical reactions, pyrene nucleation, and incipient soot formation in combustion, Proceedings of the Combustion Institute, 2017, 36, 799-806.

1134

102 B. D. Adamson, S. A. Skeen, M. Ahmed and N. Hansen, Detection of Aliphatically Bridged Multi-Core Polycyclic Aromatic Hydrocarbons in Sooting Flames with AtmosphericSampling High-Resolution Tandem Mass Spectrometry, J. Phys. Chem. A, 2018, 122, 93389349. Reactivity of Polycyclic Aromatic Hydrocarbon Soot Precursors: Implications of Localized $\pi$ Radicals on Rim-Based Pentagonal Rings, J. Phys. Chem. C, 2019, 123, 26673-26682. energies, Phys. Chem. Chem. Phys., 2019, 21, 10325-10335.

1144 